\title{
TRUNCATION OF THE DISTRIBUTION OF GROUND-MOTION RESIDUALS
}

\author{
Fleur O. STRASSER ${ }^{1 *}$, Julian J. BOMMER ${ }^{1}$ and Norman A. ABRAHAMSON ${ }^{2}$
}

\begin{abstract}
Recent studies to assess very long-term seismic hazard in the United States and in Europe have highlighted the importance of the upper tail of the ground-motion distribution at the very low annual frequencies of exceedance required by these projects. In particular, the use of an unbounded lognormal distribution to represent the aleatory variability of ground motions leads to very high and potentially unphysical estimates of the expected level of shaking. Current practice in seismic hazard analysis consists of truncating the ground-motion distribution at a fixed number $\left(\varepsilon_{\max }\right)$ of standard deviations $(\sigma)$. However, there is a general lack of consensus regarding the truncation level to adopt. This paper investigates whether a physical basis for choosing $\varepsilon_{\max }$ can be found, by examining records with large positive residuals from the dataset used to derive one of the ground-motion models of the Next Generation Attenuation (NGA) project. In particular, interpretations of the selected records in terms of causative physical mechanisms are reviewed. This leads to the conclusion that even in well-documented cases, it is not possible to establish a robust correlation between specific physical mechanisms and large values of the residuals, and thus obtain direct physical constraints on $\varepsilon_{\max }$. Alternative approaches based on absolute levels of ground motion and numerical simulations are discussed. However, the choice of $\varepsilon_{\max }$ is likely to remain a matter of judgment for the foreseeable future, in view of the large epistemic uncertainties associated with these alternatives. Additional issues arise from the coupling between $\varepsilon_{\max }$ and $\sigma$, which causes the truncation level in terms of absolute ground motion to be dependent on the predictive equation used. Furthermore, the absolute truncation level implied by $\varepsilon_{\max }$ will also be affected if $\sigma$ is reduced significantly. These factors contribute to rendering a truncation scheme based on a single $\varepsilon_{\max }$ value impractical.
\end{abstract}

\footnotetext{
${ }^{1}$ Department of Civil \& Environmental Engineering, Imperial College London, UK

${ }^{2}$ Pacific Gas \& Electric, San Francisco, California.

*Corresponding author, fleur.strasser@imperial.ac.uk
} 


\section{Introduction}

Recent studies to assess very long-term seismic hazard, such as the Yucca Mountain project in the United States (Stepp et al., 2001) and the PEGASOS project in Switzerland (Abrahamson et al., 2002), have highlighted the importance of the upper tail of the ground-motion distribution at the very low annual frequencies of exceedance (AFE) required by these projects. In particular, the use of an unbounded normal model to represent the distribution of the logarithmic groundmotion residuals in order to capture the aleatory variability $(\sigma)$ of ground motions leads to very high and potentially unphysical estimates of the expected level of shaking (Bommer et al., 2004).

As a result, it has become common practice to truncate the distribution of logarithmic groundmotion residuals at a fixed number $\left(\varepsilon_{\max }\right)$ of standard deviations $(\sigma)$. The purpose of this paper is to explore the issue of how the choice of this truncation level may be justified, with a particular emphasis on the insights offered by empirical data. This is done firstly by clarifying what information current strong-motion datasets can provide regarding the validity of the lognormal assumption, and secondly by exploring the nature of ground-motion records associated with large positive residual values, hereafter referred to as high- $\varepsilon$ records. The purpose of this exercise is to examine whether valid reasons can be found to dismiss high- $\varepsilon$ records as being unrepresentative of the ground motions that are being estimated in the context of a site-specific seismic hazard assessment. The discussion will focus primarily on the following two questions: Are the groundmotion amplitudes of high- $\varepsilon$ records large enough to matter from a hazard assessment perspective? And are there any physical mechanisms (potentially not applicable to the site for which the hazard is assessed) that could explain the large positive values of the residuals?

\section{Ground-motion residuals and variability}

For strong-motion datasets used to derive empirical ground-motion prediction equations (GMPE), the residual $\delta$ can be defined for any point in the dataset as the difference between the observed and the predicted value of the ground motion:

$$
\delta=\log \left(Y_{\text {observed }}\right)-\log \left(Y_{\text {predicted }}\right)
$$

The normalised residual $\varepsilon_{i}$ is equal to the residual divided by the standard deviation of the aleatory variability $(\sigma)$ of the predictive equation:

$$
\varepsilon=\frac{\log \left(Y_{\text {observed }}\right)-\log \left(Y_{\text {predicted }}\right)}{\sigma}
$$


Thus, the (normalised) residual is a measure of how well the predictive model fits any individual data point, as it counts the number of standard deviations that need to be added to or subtracted from the mean prediction of $\log (\mathrm{Y})$ in order to reach the observed value. It has become common practice to separate the total variability $\sigma_{\mathrm{T}}$ into variability components, namely the inter-event variability $\sigma_{\mathrm{E}}$ and the intra-event variability $\sigma_{\mathrm{A}}$. These three quantities are related through the following expression:

$$
\sigma_{T}=\sqrt{\sigma_{E}^{2}+\sigma_{A}^{2}}
$$

The inter-event variability $\sigma_{E}$ (also called event-to-event variability and noted $\tau$ by some authors) can be interpreted as the variability in ground motion that is caused by differences between events that are not accounted for by the explanatory variables characterising the source, such as magnitude and style-of-faulting. The intra-event variability $\sigma_{\mathrm{A}}$ (also called record-to-record variability and noted $\sigma_{\mathrm{r}}$ by some authors) can be interpreted as the random variability in ground motion amongst receivers in the same site class and located at the same distance from the source, for a single event.

In the remainder of this paper, the following conventions are used to refer to the residuals corresponding to the different variance components: raw residuals, as defined in Equation (1), are designated by the symbol $\delta$, whereas residuals normalised by the appropriate variability component, as defined in Equation (2), are designated by the symbol $\varepsilon$. When necessary, the type of residual is identified by the subscript T, A or $E$ for total, intra-event and inter-event residuals, respectively. Note that whereas $\delta_{T}$ is equal to the sum of $\delta_{E}$ and $\delta_{A}, \varepsilon_{T}$ is equal to a weighted sum of $\varepsilon_{E}$ and $\varepsilon_{A}$, with the weights depending on the ratio of $\sigma_{E}$ and $\sigma_{A}$, as a consequence of Equation (3).

In the framework of probabilistic seismic hazard analysis (PSHA), when the AFE of a given level of ground motion $Y_{0}$ is calculated through integration over all possible earthquake scenarios in terms of magnitude and distance, the variability of the ground motion must be considered (Bommer and Abrahamson, 2006), resulting in the triple integral given in Equation (4):

$$
\operatorname{AFE}\left(Y_{0}\right)=\sum_{j=1}^{N_{\text {sources }}} N_{j}\left(M_{\min }\right) \iiint_{\varepsilon, r, m} f_{M R}(m, r) f_{E}(\varepsilon) I\left(y(m, r, \varepsilon) \geq Y_{0} \mid m, r, \varepsilon\right) d m d r d \varepsilon
$$

where $f_{M R}$ is the joint probability density function of magnitude $\mathrm{M}$ and source-to-site distance $\mathrm{R}$, evaluated for a given scenario event $(M=m, R=r), f_{E}$ is the probability that the ground motion deviates $\varepsilon$ standard deviations from its median value, and $I$ is an indicator function equal to 1 when the target ground-motion level is exceeded for a given $(m, r, \varepsilon)$ triplet, and to 0 otherwise. Note that even in the case that $\sigma$ is a function of magnitude or distance, $(m, r)$ and $\varepsilon$ are 
statistically independent as a result of the regression process, and therefore the joint probability of occurrence of a $(m, r, \varepsilon)$ triplet, $f_{M R E}$, can be expressed as the product of $f_{M R}$ and $f_{E}$ (Bazzurro and Cornell, 1999). The sum to the left of the triple integral captures the contribution from several sources, $N_{j}$ being the annual number of earthquakes exceeding the minimum magnitude $M_{\min }$ for source $j$. Since $m$ and $r$ are bounded by the source zone geometry and the magnitude limits considered in the recurrence relationships, the behaviour of the indicator function $I$ will be entirely dictated by the upper tail of the residual distribution once the largest magnitude and shortest distance have been reached. In other words, given an unbounded distribution of residuals, any level of ground motion is deemed possible, provided a sufficiently low probability level is considered. This is at odds with the assumption that the maximum ground motions that can be experienced at the ground surface are finite, as a result of energy conservation and finite material strength (Bommer et al., 2004). Therefore, the aim of choosing a truncation level ultimately is to exclude unphysical levels of ground motion (i.e., levels of ground motion that cannot be obtained by any combination of physical processes, however unlikely), while preserving the convenience of a simple mathematical model to represent the bulk of the data. In practice, however, both the choice of the truncation level adopted and the corresponding justification do not always acknowledge this ideal goal, as will become apparent later in this paper. Computational convenience has also led to the practice of truncating the ground-motion distribution at a fixed

number $\varepsilon_{\max }$ of standard deviations, which in particular does not depend on magnitude, distance, or the level of ground motion considered.

\section{Selection of Truncation Level}

Although it has been brought to light in the context of PSHA, the issue of the range of values that can be taken by the ground-motion residuals is also relevant in a deterministic framework. Indeed, the current practice in deterministic seismic hazard analysis (DSHA) of presenting the $84^{\text {th }}$ percentile of the ground motion for a given scenario earthquake as the 'worst-case scenario' ground motion implies a truncation of the ground-motion distribution at $\varepsilon=1$. Strictly speaking, the worst-case scenario should be the boundary between physically possible and unphysical ground motions, and thus very similar in nature to the ideal choice of upper integration bound for $\varepsilon$ in Equation (4). In a fully deterministic framework, one would expect the 'worst-case scenario' to correspond to the level of ground motion that would be expected if all the most unfavourable conditions were satisfied simultaneously, rather than a deviation from the median ground motion based on the claim that "with the use of a mean +1 S.D. to bracket the vagaries in recorded ground motions, the deterministic procedure encompasses uncertainty inasmuch as is humanly possible" (Krinitzsky, 2002). Indeed, the use of an unbounded probability distribution to model the behaviour of the ground motion, and the underlying intent of defining ground-motion estimates in 
relation to the median value, i.e. according little importance to the ideal upper bound defining the threshold between physically possible and unphysical ground motions, provides an interesting parallel between DSHA and PSHA. Both approaches provide a mechanism to back away from the most severe motions that could possibly occur at the site; DSHA by choosing $\varepsilon_{\max }$, PSHA by selecting - often arbitrarily (Bommer, 2006) - an AFE. As a result, the selection - and indeed the interpretation - of a truncation level for ground motions is just as unavoidable an issue for deterministic seismic hazard analysis (DSHA) as it is for PSHA. In both cases, $\varepsilon_{\max }$ appears to be the 'missing piece' of the puzzle (Bommer, 2002).

The questions that then arise are: which value should $\varepsilon_{\max }$ take? And how can this choice be justified? The answer to the first of these questions depends on the importance of the project under consideration, which in a probabilistic context will determine the target AFE value. Figure 1, shows the effect of different values of the truncation level $\varepsilon_{\max }$ on hazard estimates. The curves are for a fictitious rock site located at $25 \mathrm{~km}$ from the boundary of a hypothetical seismic source zone with a maximum magnitude of 7.5; the $\mathrm{A}$ - and b-values in the recurrence relationship are 2 and 0.7 , respectively, which is representative of a region of low-to-moderate seismicity. The ground motions have been computed using the predictive equation of Ambraseys et al. (1996), for which $\sigma=0.25$ (in $\log _{10}$ units). For structures of normal importance, associated with AFE values of the order of $10^{-2}$ to $10^{-3}$, the contribution of the tails of the ground-motion distribution is negligible, therefore the choice of the truncation level does not have a noticeable influence on the hazard results in this example. On the other hand, the truncation level has a significant effect at the low AFEs $\left(10^{-6}\right.$ to $\left.10^{-8}\right)$ considered in the very-long-term seismic hazard assessments mentioned previously. The AFE at which the choice of the truncation level starts affecting the hazard results is a function of the annual number of earthquakes, and is expected to be higher in high-activity regions than in low-activity regions. In the example shown, the effect of the choice of the truncation level is most pronounced for values of $\varepsilon_{\max }$ ranging from 1 to 5 . This supports the choice of the truncation level in widely used seismic hazard analysis codes, such as EQRISK (McGuire, 1976), which fix the truncation level at $\varepsilon_{\max }=6$ : numerically, this approximates an unbounded distribution even at the very low probability levels discussed above.

[Figure 1 about here]

Another, more common type of justification for selecting $\varepsilon_{\max }$ is the implication in terms of probability. For instance, values beyond $\varepsilon_{\max }$ are excluded because they correspond to probabilities of exceedance ( $\mathrm{POE}$, conditional on a given magnitude and distance) that are thought to be too low to matter in the computation of the hazard. Table 1 summarises the truncation levels to be adopted in order to exclude ground motions with conditional POEs lower than a series of characteristic thresholds (1-in-10, 1 -in-100, etc.). It is important to acknowledge that the level at which probabilities become 'too low to matter' depends on the target AFE 
considered, as well as on the annual rate of earthquake occurrence. Thus, the 1-in-10,000 conditional ground-motion (corresponding to $\varepsilon=3.72$ ) may appear negligible for an engineering project of normal importance considering an AFE of the order of $10^{-3}$, but it would be difficult to justify ignoring it when the target AFE is $10^{-7}$ or $10^{-8}$.

\section{[Table 1 about here]}

Another point worth noting is that the interpretation of this type of truncation is far more straightforward when the truncation level $\varepsilon_{\max }$ is determined from a given conditional POE, rather than the other way round. In particular, integer values of $\varepsilon_{\max }$ do not provide very transparent interpretations: truncating at $\varepsilon_{\max }=1$ means ignoring ground motions with a conditional POE of less than 1 -in- 6.3 , truncating at $\varepsilon_{\max }=2$ corresponds to a cut-off at the 1 -in- 44 conditional ground motion. In both DSHA and PSHA, a more rational approach would be to select the desired POE rather than the $\varepsilon_{\max }$ value; for example, for a given magnitude-distance scenario, a motion with a 1-in-10 POE would yield an $\varepsilon_{\max }$ value of 1.3 (Table 1). Similarly, in PSHA, a justification similar to that employed by Romeo and Prestininzi (2000), who performed a truncation at $\varepsilon_{\max }=2$ on the basis that "stronger motions are considered to be unlikely", would be easier to relate to acceptable risk levels if it were specified in terms of a POE rather than an integer value of $\varepsilon$.

\section{Empirical Strong-Motion Datasets and the Truncation Issue}

So far, the discussion has included numerical and purely statistical arguments for selecting the truncation level. However, in practice, this choice is often related to the behaviour of empirical strong-motion datasets. In the context of seismic hazard analysis, the truncation issue has been discussed by a number of authors (Zemell, 1984; Bernreuter et al., 1989; Anderson and Brune, 1999; Abrahamson, 2000a; Romeo and Prestininzi, 2000), but there is a general lack of consensus regarding the truncation level to adopt, with proposals ranging from $1 \sigma$ (e.g., Marin et al., 2004) to $4 \sigma$ (e.g., Bernreuter et al., 1989). To a certain extent, differences between the proposed values could be linked to the coupling between $\sigma$ and $\varepsilon$, particularly in the Bernreuter et

al. (1989) study where the experts were asked to evaluate both $\sigma$ and $\varepsilon_{\max }$. Indeed, since the normalised residual $\varepsilon$ can be interpreted as the number of standard deviations $\sigma$ a given observation lies from the predicted mean value, the same observation can be associated with a large value of $\varepsilon$ if the ground-motion distribution is narrow (small $\sigma$ ) or a small value of $\varepsilon$ if the distribution is broad (large $\sigma$ ), assuming the predicted mean value is the same. Therefore, unless the selection of $\varepsilon_{\max }$ is based on purely statistical criteria (e.g., the level corresponding to the 1-in10,000 ground motion), the values of $\varepsilon_{\max }$ put forward are implicitly referred to a given groundmotion model. Hence, some of the differences in $\varepsilon_{\max }$ values suggested could be explained by differences in the ground-motion models employed. 
The coupling between $\sigma$ and $\varepsilon$ is, however, unlikely to be the sole explanation for the lack of consensus regarding $\varepsilon_{\max }$, since values of $\sigma$ have remained in the same range of values $(0.2$ to $0.3 \log _{10}$ units for PGA) for many years. Numerous attempts have been made at reducing the scatter in empirical GMPE over the past 30 years, but despite an increase in the number of available records and the inclusion of additional variables in the equations, the values of variability have not been found to decrease significantly. Figure 10 of Douglas (2003a) summarises the values of "uncertainty" (defined there as the ratio of the $84^{\text {th }}$ to the $50^{\text {th }}$ percentile) for about 120 predictive equations published between 1973 and 2002. The values of "uncertainty" range from 1.26 to 2.77 (i.e. $\sigma=0.10$ to 0.44 , in $\log _{10}$ units) with most values lying in the range 1.5 to 2.0 (i.e. $\sigma=0.18$ to 0.30 ). No consistent reduction of these ranges over time can be observed, and "uncertainties" from recently derived equations still fall in the 1.65 to 2.25 range. Douglas and Smit (2001) discuss the concept of pure error (Draper and Smith, 1981, pp. 33-42) applied to ground-motion predictive equations. For a given set of records, pure error analysis provides a lower bound on the standard deviation possible by fitting any functional form, no matter how complex, to the data once a set of explanatory variables has been selected. Douglas and Smit (2001) conclude that the variability currently found in empirical predictive equations are about the best achievable without including more independent parameters. Recent studies (Chen and Tsai, 2002; Atkinson, 2006) making use of strong-motion data recorded on dense networks provide some hope for a reduction in $\sigma$ if the individual components of variability (e.g., inter-event and intra-event) can be better constrained. A narrower ground-motion distribution would reduce the influence of the tails on seismic hazard estimates, and therefore a significant reduction in $\sigma$ could provide a practical alternative to defining $\varepsilon_{\max }$, without, however, solving the theoretical issue of defining the extent of physically possible ranges of ground-motion values.

The values put forward for $\varepsilon_{\max }$ have been based mainly on the representation of the residuals in quantile-quantile or normal probability plots. Such plots display either the theoretical quantiles or the probability associated with a normal distribution against the quantiles of the residuals observed in the dataset; if the points fall along a line, the empirical distribution can be considered approximately normal. If the distribution is truncated, then a quantile-quantile plot becomes horizontal at large values on the y-axis. Figure 2 shows examples of quantile-quantile plots for the total normalised residuals $\left(\varepsilon_{T}\right)$ derived from an empirical GMPE (Abrahamson and Silva, 2005, upper left panel), and random samples of the same size (2,791 points) drawn from an untruncated normal distribution (upper right panel) as well as from normal distributions truncated at $\varepsilon_{\max }=2.5$ and $\varepsilon_{\max }=3.0$ (bottom panels).

\section{[Figure 2 about here]}

The empirical dataset shows a good fit to the lognormal distribution out to a level corresponding to $+/-2.5 \sigma$, beyond which deviations from the lognormal distribution are observed. A similar 
behaviour has been found for other datasets used to derive empirical ground-motion prediction equations (GMPE), the range over which good agreement with a normal distribution can be assumed varying from $+/-2$ to $3.5 \sigma$, depending on the equation (Strasser and Bommer, 2004).

A fundamental observation to be made about quantile-quantile and normal probability plots is that while they may provide conclusions regarding the validity of the lognormal assumption over a certain range of $\varepsilon$ values, the observed deviations do not constitute sufficient proof to discount a normal distribution beyond this range. Indeed, part of the deviation of the observed residuals from the tails of the normal distribution is likely to be related to an 'end effect' caused by the fitting of a continuous distribution to a discrete dataset. The sample size $\left(N_{P T S}\right)$ controls the maximum value of the normalised residual $\left(\varepsilon_{\text {max }}^{*}\right)$ that could be observed if the residuals were normally distributed via the relation:

$$
\varepsilon_{\max }^{*}=\Phi^{-1}\left(1-\frac{1}{N_{P T S}}\right)
$$

where $\Phi^{-1}$ is the inverse cumulative probability density function of the standard normal distribution. Figure 3 illustrates the relation between $N_{P T S}$ and $\varepsilon^{*}{ }_{\text {max }}$.

\section{[Figure 3 about here]}

For a sample of size $N_{P T S}$, any point for which the observed normalised residual $\varepsilon_{i}$ is larger than $\varepsilon_{\text {max }}^{*}$ will necessarily deviate from the standard normal distribution (e.g., in a quantile-quantile or normal probability plot) because the theoretical probability of exceedance is smaller than the smallest empirical probability that can be derived from the dataset $\left(1 / N_{P T S}\right)$ :

$$
p_{\text {Theo }}\left(\varepsilon \geq \varepsilon_{i}\right)=1-\Phi\left(\varepsilon_{i}\right) \leq 1-\Phi\left(\varepsilon_{\max }^{*}\right)=\frac{1}{N_{P T S}}
$$

A similar observation can be made for points with observed normalised residuals smaller than - $\varepsilon_{\text {max }}^{*}$. For empirical predictive equations, the number of data points considered is of the order of several hundreds to several thousands, which roughly corresponds to $\varepsilon^{*}{ }_{\text {max }}=2.5$ to 3.5 (Figure 3). As a result, the observed deviations cannot be interpreted unambiguously as showing the lack of normality of the data. Assuming there are sufficient data to exclude the influence of end effects, the fact that the quantile-quantile plot becomes flatter merely indicates that the empirical distribution is narrower than expected for a lognormal distribution above a certain level, not that ground motions beyond that level do not occur. Indeed, datasets from recent GMPE (e.g., Lussou et al., 2001; Chang et al., 2001; Berge-Thierry et al., 2003; Bommer et al., 2003; Ambraseys et al., 2005; Abrahamson and Silva, 2005) routinely include data points associated with residuals as large as 3 or 4 , as summarised in Table 2 . 
[Table 2 about here]

Restrepo-Vélez and Bommer (2003) explore the alternative approach of fitting the data to a truncated lognormal distribution (the Upper Limit Lognormal, or ULLN, distribution) instead of the traditional unbounded lognormal distribution. This requires the introduction of an additional parameter, namely the upper bound $\alpha$. A practical problem is that existing algorithms for obtaining parameters of the ULLN (Bezdek and Solomon, 1983) are highly sensitive to the initial choice of $\alpha$. When the ULLN is fitted to the residuals of a strong-motion data set used for deriving a groundmotion prediction equation, using an approach that determines a as part of the solution, the results generally yielded values corresponding to about six standard deviations above the mean, which cannot be verified with the existing data. A more fundamental limitation, which is shared by all statistical approaches, is the implicit assumption that the underlying dataset is a representative sample of the population of all physically possible ground motions. The limited amount of data constituting the tails of the distribution makes it difficult to examine the validity of this assumption.

In view of the difficulty to prove (or disprove) the validity of the normal distribution at the tails of the residual distribution, it is unclear how the most extreme $\varepsilon$ values associated with the empirical distribution should be interpreted in statistical terms, since any deviation from the normal model implies that the conditional POEs assumed for a given level of ground motion are approximate. Similarly, it could be argued that the integration over $\varepsilon$ in Equation (4) should not be carried out assuming an unproven normal distribution. It should be pointed out, however, that the alternative of integrating solely over the range of $\varepsilon$ over which the data has been found to be in good agreement with the normal model assumes an equally unproven distribution (e.g., truncated), which may be a poorer fit to the empirical data (Figure 2). The rest of this paper further investigates the nature of the most extreme residuals in empirical ground-motion datasets in the light of physical parameters associated with the corresponding accelerograms, focusing more particularly on high- $\varepsilon$ records.

\section{How Significant are High-Epsilon Accelerograms?}

A preliminary point to address in the consideration of high- $\varepsilon$ accelerograms is their engineering significance. Indeed, if it could be shown that large positive values of epsilon are exclusively associated with weak motions (from small magnitudes and/or large distances) that are unlikely to cause damage, this could give some support to truncating the ground motion at a comparatively low value of epsilon for magnitude-distance pairs corresponding to stronger ground motions, using magnitude- and distance dependent bounds for the integration over epsilon in Equation (4). This in turn would allow a significant reduction of the expected ground-motion values for a given 
AFE, without any loss in safety, since this reduction would result solely from the exclusion of unphysical scenarios. However, in practice, demonstrating the association between large residual values and weak motions is hampered by sampling issues: even if no strong-motion observations associated with high residuals are encountered, this cannot unambiguously be interpreted as a proof of their non-existence.

Nevertheless, the 15 highest residuals of the Bommer et al. (2003) dataset have been examined to check whether the lack of distinctive patterns expected for the overall residual dataset in a wellconditioned regression is shared by the subset constituted by these extreme observations. Since this subset much smaller than the total dataset, trends could exist within this subset that would not be apparent from an examination of the complete dataset. Inspection of the site classes and styles-of-faulting associated with these high residuals lead to the conclusion that the subset of highest residuals does not show any correlation with any of the basic explanatory variables used in regression analyses. The exercise has been repeated with the 15 highest residuals of the Berge-Thierry et al. (2003) dataset, with similar results.

The analysis shows that the largest normalised residuals seem to be predominantly associated with ground motions of little engineering significance. This is illustrated in Figure 4 for the highest normalised residuals from the Bommer et al. (2003) PGA equation. The left panel identifies the position of the residuals with respect to observed and predicted ground-motion. The right panel shows their position in magnitude-distance space. The numbers in the squares correspond to the rank of each record ( 1 for the highest residual, and so on). Some of the highest normalised residuals ( 3 and 4 ) are located very centrally in the dataset. The dashed heavy line corresponds to the approximate boundary of damaging motions inferred by Bommer et al. (2001) based on the work of Martínez-Pereira and Bommer (1998), who correlated several ground-motion parameters with Modified Mercalli Intensity (MMI) to establish thresholds (which can be classified as necessary but not sufficient conditions) for motions to be damaging to engineered structures, i.e., $\mathrm{MMI} \geq \mathrm{VIII}$. The line has been constructed using a database of about 1,500 records, for which a number of ground-motion parameters (specifically PGA, PGV and Arias intensity) all simultaneously exceeded the established threshold for potential damage. The approximate boundary of damaging motions - which is intended to be indicative rather than genuinely limiting is then derived by reduction of the M-R space, enveloping those records for which all damage potential criteria are satisfied simultaneously.

\section{[Figure 4 about here]}

It is noteworthy that in the example shown, most of the high normalised residuals lie below this line, and that a similar pattern has been observed for other datasets associated with equations including a constant $\sigma$ (e.g., Abrahamson and Silva, 2005). If a magnitude-dependent $\sigma$ is considered (e.g., Abrahamson and Silva, 2007), the values of the normalised residuals will 
increase at large magnitudes and decrease at small magnitudes, which might lead to a different pattern.

When normalised by the total number of datapoints on each side of the line, the number of high residuals are similar above and below the line, indicating that overall, these high residuals follow the same pattern as the whole dataset. However, in all cases, a few high residuals associated with ground motions strong enough to lie above the potential damage line have been observed. Bearing in mind that records for which strong site effects related to surface geology or topography have been excluded before the derivation of the potential damage line, this raises the question whether high- $\varepsilon$ records can be related to specific physical processes that would not necessarily be relevant in a generic ground-motion prediction context. This issue is explored using a subset of the strong-motion database developed by the Pacific Earthquake Engineering Research (PEER) Center as part of the Next Generation Attenuation Project (NGA) to develop new groundmotion models.

\section{Selection of High- $\varepsilon$ Accelerograms from the PEER-NGA Database}

Rejection of observations deviating significantly from the predictions is a well-established practice in statistics (e.g., Hawkins, 1980; Barnett and Lewis, 1994). A large number of tests of varying complexity are available to detect observations which are not only "extremes" (i.e., belong to the tails of the observed distribution) but are also "statistically unreasonable when viewed as extreme[s]" (Barnett and Lewis, 1994, p. 37). Such observations are labelled "discordant outliers". Simple statistical rules commonly used to detect potential outliers, such as the boxplot rule or Grubbs' test, consider thresholds around the $2.5 \sigma$ level. The boxplot rule labels data points as potential outliers if they lie 1.5 times the interquartile range (difference between the third and first quartiles) above the third quartile of the dataset, which for the standard normal distribution corresponds to $\varepsilon=2.69$. Grubbs' test is a recursive test for outlier detection which considers the absolute value of the largest normalised residual observed in the sample as a test statistic and compares it to a tabulated critical value, which depends on the sample size, N. At the $5 \%$ significance level, the critical values tabulated range from 2.29 for $\mathrm{N}=10$ to 3.38 for $\mathrm{N}=100$.

Note that all these statistical procedures are based on test statistics assuming the target population to be infinite (i.e., a true normal distribution). Barnett and Roberts (1993) [quoted in Barnett and Lewis (1994), p.447] have, however, shown that when the target population is reduced to a finite population and the test statistic is applied to samples drawn from this population, the critical value of the test statistic is non-unique, and depends on the finite population used in the first stage. In other words, no discordancy test is available for the detection of potential outliers in a finite population, even in the case where the distributional form of this 
population is known. This means that a maximum value of epsilon cannot be fixed on a purely statistical basis, but requires additional constraints.

Many of the statistical procedures for outlier detection have been derived to quickly identify clearly erroneous data points in large samples of data (e.g., automated measurements in laboratory experiments) for which individual examination of the data would be impractical. Strongmotion datasets, on the other hand, are usually compiled through a careful selection process (e.g., Douglas, 2003b) and it is therefore unlikely that any of the records identified as potential outliers applying a statistical procedure to the residuals will be obviously unsuitable for regression, since such records should have been eliminated at an earlier stage. Instead, the objective of this study is to examine records associated with large positive epsilons, and to investigate whether a physical justification can be found for their exclusion from the dataset, on the basis of their representing specific conditions not relevant to the general application of the ground-motion prediction equation. These records are selected from the strong-motion database developed as part of the NGA project.

The NGA database (PEER, 2005) includes 3551 records from 173 events and 1455 stations. After exclusion of records which are of insufficient quality or documentation level, a subset consisting of 2791 records from 102 events and 1150 stations is used for the regression analysis. The ground-motion model is that of Abrahamson and Silva (2005), a preliminary version of the Abrahamson and Silva (2007) model which effectively constitutes an update of the Abrahamson and Silva (1997) model for the prediction of 5\%-damped pseudo-spectral accelerations. The choice of the of Abrahamson and Silva (2005) model was mainly driven by the availability of data at the time the main body of this study was carried out. In order to assess the general nature of the results, the set of records selected on the basis of their large positive epsilon with respect to the Abrahamson and Silva (2005) model is also examined in terms of its residual values with respect to the Abrahamson and Silva (2007) model, as well as other predictive equations derived in the NGA project that have since been made available (e.g., Boore and Atkinson, 2006; Chiou and Youngs, 2006; Campbell and Bozorgnia, 2006). Figure 5 shows that the number of records with $\varepsilon_{\mathrm{T}} \geq 2.5$ is reduced in the more recent models, which is likely to be a consequence of the inclusion of additional parameters in the predictive model. Nevertheless, a significant proportion of the records associated with the most extreme residuals remains above the selection threshold for all predictive models considered.

\section{[Figure 5 about here]}

In the Abrahamson and Silva (2005) model, the source is represented by the moment magnitude $M_{w}$, the style-of-faulting, and the fault aspect ratio. The path is represented by the rupture distance $\mathrm{R}_{\text {rup }}$ (e.g., Abrahamson and Shedlock, 1997), and the source-to-site azimuth (which determines the hanging wall or footwall location of the station). Site conditions are represented by 
the average shear-wave velocity over the top $30 \mathrm{~m}, \mathrm{~V}_{\mathrm{s}, 30}$. The horizontal component definition used is the median value of the geometric mean of the two horizontal components rotated over the non-redundant range of rotation angles (GMRotD50), as defined by Boore et al. (2006). The relationships between this and other horizontal component definitions have been investigated by Beyer and Bommer (2006).

The regression is carried out using the one-stage maximum-likelihood random effects approach described by Abrahamson and Youngs (1992). This approach allows a meaningful partitioning of the total variability $\sigma_{\mathrm{T}}$ between the inter-event variability $\left(\sigma_{\mathrm{E}}\right)$ and the intra-event variability $\left(\sigma_{\mathrm{A}}\right)$, with all events having the same weight in the determination of the inter-event variability and all records having the same weight in the determination of the intra-event variability. Consistent with findings from other equations, the inter-event variability $\sigma_{E}$ is smaller than the intra-event variability $\sigma_{\mathrm{A}}$ and is associated with a larger uncertainty, as shown in Figure 6 . The total variability is of the order of 0.6 to 0.7 In units ( 0.26 to $0.30 \log _{10}$ units) and appears to be affected by peaks in inter-event variability at $0.1 \mathrm{~s}$ and in intra -event variability at $2 \mathrm{~s}$.

[Figure 6 about here]

The quantile-quantile plots of the normalised total $\left(\varepsilon_{T}\right)$ and intra-event $\left(\varepsilon_{A}\right)$ residuals of this dataset at selected response periods are shown in Figures 7 and $\underline{8}$, respectively. Values of $\varepsilon_{\top}$ range from -4 to +4 , while values for $\varepsilon_{A}$ almost span the range -5 to +5 . A good fit to the normal distribution is observed in both cases up to at least the $3.5 \sigma$ level. Extreme residual values tend to be higher for intra-event residuals $\left(\varepsilon_{A}\right)$ than for inter-event residuals $\left(\varepsilon_{E}\right)$, which is mainly a consequence of the difference in sample size, with the number of records determining the $\varepsilon_{A}$ distribution being an order of magnitude larger than the number of events determining the $\varepsilon_{\mathrm{E}}$ distribution (see Figure 3).

\section{[Figures 7 and $\underline{8}$ about here]}

Very little deviation is observed for the tails of the distribution for the total residuals, although some deviation of $\varepsilon_{T}$ from the normal distribution would be expected as a result of the differences existing between the number of records contributed by the various earthquakes. There do not appear to be any obvious 'visual outliers' for either $\varepsilon_{\mathrm{T}}$ and $\varepsilon_{\mathrm{A}}$. This raises the question of the criterion to employ for the selection of potential outliers. In the context of this exercise, 'highepsilon' records are defined as those with epsilon values in excess of 2.5. The selection is based on the total residual, since this is the variable most commonly used in probabilistic seismic hazard calculations to account for ground-motion variability. Records are selected if $\varepsilon_{T}$ exceeds the threshold level for any of the 15 response periods considered: $0.0 \mathrm{~s}$ (PGA), $0.02 \mathrm{~s}, 0.05 \mathrm{~s}, 0.10 \mathrm{~s}$, $0.15 \mathrm{~s}, 0.20 \mathrm{~s}, 0.30 \mathrm{~s}, 0.40 \mathrm{~s}, 0.50 \mathrm{~s}, 0.75 \mathrm{~s}, 1.0 \mathrm{~s}, 1.50 \mathrm{~s}, 2.0 \mathrm{~s}, 3.0 \mathrm{~s}$ and $4.0 \mathrm{~s}$. 
The reasons for choosing the $+2.5 \sigma_{\mathrm{T}}$ level are threefold: firstly, Table 2 shows that all datasets examined in a preliminary study (Strasser and Bommer, 2004) include data points with $\varepsilon_{T} \geq 2.5$, which therefore constitutes the lowest possible selection value. Secondly, for a sample of 2,791 points, the theoretical fractile corresponding to the smallest observable frequency is the $99.97^{\text {th }}$ percentile, corresponding to $\varepsilon=3.4$, which means that records beyond that level can be expected to be affected by sample size effects, as discussed previously. For a meaningful interpretation of large-epsilon records in terms of physical factors, it is desirable to use a selection threshold that is significantly lower than this value. Finally, this level is roughly consistent with threshold levels commonly used in simple statistical tests to detect potential outliers, such as the boxplot rule and Grubb's test.

The application of the above criterion results in the selection of 105 records from 24 events. Figure 9 summarises the contributions of selected events to the dataset used in the regression, and to the selected subset, highlighting the impact of the number of records considered for each event in the regression. As a result, the events that are part of the selected subset are divided into 4 categories, as defined in Table 3 . Most events in the selection contribute only one or two records, with the notable exception of Chi-Chi aftershocks Chi-Chi-05 and Chi-Chi-06 and the Loma Prieta earthquake, which contribute 56, 10 and 9 records, respectively. All styles-of-faulting are represented, although there is a predominance of reverse and reverse-oblique records due to the composition of the underlying dataset. Similarly, records from all NEHRP site classes are encountered in the selection, but there is a predominance of site class $C$ and $D$ records reflecting in part the important contribution of the Taiwanese data. An interesting point to note is that with the exception of the Chi-Chi mainshock, all of the events in categories I and II are buried rupture events. The predominance of these events in the high- $\varepsilon_{T}$ selection is consistent with the suggestion that buried rupture events are associated with higher ground motions than events rupturing the surface (Kagawa et al., 2004). However, Table 3 shows that a comparable number of records is selected for the events in this category when the residual datasets from the Abrahamson and Silva (2007) and Chiou and Youngs (2006) models are used, although these models include a term accounting for the depth to the top of the rupture. Finally, only 11 records exceed the $\varepsilon_{\mathrm{T}}=3.4$ level above which sample size effects are expected to affect the residual values.

[Figure 9 about here]

[Table 3 about here] 


\section{Physical Interpretations of High- $\varepsilon$ Records in the PEER-NGA Database}

For each record of the selection, the literature has been searched for interpretations in terms of physical mechanisms that have been put forward to explain the large positive residuals that correspond to large-epsilon records in the NGA database. Not all records in the selection are discussed, the purpose of this section being to highlight the issues associated with finding physical explanations for large positive epsilons. The reader is referred to Strasser and Bommer $\underline{(2005)}$ for a more comprehensive discussion of the physical factors affecting individual records.

\section{Category l: Records from the Chi-Chi, Taiwan, sequence}

Data from the mainshock and five larger aftershocks of the 1999 Chi-Chi, Taiwan, sequence represent more than $50 \%$ of the total dataset, and it is therefore not surprising to find records from these events in the high-epsilon selection. What is surprising, however, is the fact that one of the aftershocks (Chi-Chi-05) contributes 56 records, while the mainshock and the other aftershocks only contribute between 1 and 10 records, respectively; this is striking because the aftershocks have similar magnitudes and contribute comparable numbers of records. Examination of the inter- and intra-event residuals reveals that this pattern is strongly influenced by the value of the inter-event residuals $\varepsilon_{\mathrm{E}}$, summarised in Figure 10. In view of the large number of records contributed to the regression dataset, the inter-event residuals $\delta_{E}=\varepsilon_{E} \sigma_{E}$ of the Chi-Chi events are almost identical to the event averages of the total residuals $\left\langle\delta_{T}\right\rangle=\left\langle\varepsilon_{T} \sigma_{T}\right\rangle$ (the brackets indicating the average taken across the records from an individual event), and therefore the normalised inter-event residuals $\varepsilon_{\mathrm{E}}$ give an indication of the overall behaviour of the ground motions recorded during each event.

\section{[Figure 10 about here]}

Ground motions from the Chi-Chi mainshock have been noted for their low amplitudes when compared to predictions from GMPE based on predominantly Californian data (e.g., Boore, 2001). The ground motions recorded during 6 larger aftershocks, however, have been found to agree reasonably well with these predictions (Wang et al., 2004), which would imply that the ground-motions from Chi-Chi-05 are not anomalously high. In fact, the ground-motion amplitudes are comparable to those observed during the 1984 Morgan Hill event, which has the same magnitude $\left(M_{w}=6.2\right)$ as Chi-Chi-05 and contributes mainly negative intra-event residuals at high frequencies. Even the Coyote Lake Dam record from the Morgan Hill event, often discussed because of its high PGA value (e.g., Abrahamson and Darragh, 1985; Boore et al., 2004), although associated with $\varepsilon_{A}$ values ranging from 0.85 to 1.54 at high frequencies ( $T \leq 0.5 \mathrm{~s}$ ), does not exceed the $+1 \sigma$ level in terms of total normalised residual. The conclusion from this is that the high residuals observed for Chi-Chi-05 are caused not so much by large ground motions as by a markedly different behaviour from the other aftershocks, resulting in an unusually large interevent variability for this sequence. 
This variability could be related to the complex source process involved in this sequence. Based on geological information and waveform inversions, several authors concluded that the aftershock sequence involved the rupture of two conjugate fault planes (e.g., Kao et al., 2002; $\underline{\text { Chen et al., }}$ 2002): the shallowly eastward-dipping Chelungpu Fault which ruptured during the mainshock, and a steeply westward-dipping conjugate plane. Chi-Chi-05 seems to be located at the junction between the two planes, which results in ambiguities about the source mechanism of the event. Uncertainties in the fault geometries associated with these aftershocks have also been noted by Chi and Dreger (2004), who inverted strong-motion data to determine the slip distributions of these events. The same authors also noted that the differences in dip between events resulted in different spatial distribution of the ground motions, due to radiation pattern and directivity effects. The aftershock inter-event residuals shown in Figure 10 appear to be well correlated with the centroid depths of the main asperities as given by $\mathrm{Chi}$ and Dreger (2004). Including this parameter in the regressions could potentially reduce the apparent inter-event variability observed for the Chi-Chi aftershock sequence, and thus reduce the number of accelerograms satisfying the high- $\varepsilon$ selection criterion.

Very few individual analyses of the accelerograms recorded during the Chi-Chi-05 event could been found in the literature. Lee et al. (2001) have carried out a reassessment of Taiwanese strong-motion recording sites, providing a list of stations for which site effects influencing the data have been identified. However, no direct link between these stations and high residual values could be established. The normalised total and intra-event residuals for stations from the Taichung (TCU) array, which contributes the bulk of the selected data due to its proximity to the source, are shown against response period in Figure 11. The plots show residuals for this aftershock, as well as for the mainshock (NGA EQ \#137) and for aftershock Chi-Chi-06 (NGA EQ \#175), whose source characteristics appear to be the closest to those of aftershock Chi-Chi-05. Except for station TCU095, which corresponds to the only record selected from the mainshock and is possibly associated with a site effect, the stations from the TCU array show little variation in terms of their residual pattern against period, particularly in terms of total residual. The absence of clear gaps between the lines points to an almost continuous sampling of the tails of the distribution, rather than the fundamentally different character that would be expected for discordant outliers. Station TCU129, which features among the selection, has been associated with structural effects of the foundation pier to which the instrument is bolted (Wen et al., 2001), but does not present a particularly conspicuous behaviour in terms of residuals.

[Figure 11 about here]

The discussion above leads to the conclusion that the large epsilons contributed by Chi-Chi-05 have to be considered as random outliers, i.e., outliers caused by the intrinsic (or currently unexplained) variability of the ground motions rather than by some particular physical mechanism 
not included in the regression; however, it also appears that the large inter-event variability associated with the Chi-Chi sequence may be associated with a complex source process, which in turn can be related to regional tectonics. It has been suggested that the peculiar tectonic regime around Taiwan, associated with subduction of the Philippine Sea plate under the Eurasian plate to the north, and subduction of the Eurasian plate beneath the Philippine Sea plate to the south, may have led to shallow crustal tectonics that are different from those observed in other continental margins (e.g., Seno et al., 2000). The question that arises from this is how transportable ground-motion variability and the resulting residual values actually are: for instance, is the level of source complexity presumably observed in the Chi-Chi data representative of the source complexity in other tectonic settings such as stable continental regions? A corollary question is whether the inter-event variability observed during a single earthquake sequence can be considered representative of inter-event variability on a regional scale.

\section{Category II: Records from well-recorded Californian events}

The records in category II (Table 2) are best-suited for the analysis in terms of causative physical factors, since the number of records contributed by the events is large enough to warrant extensive studies of the ground motion, but still small enough to allow the selection and analysis of individual records.

This subset includes the largest residual found in this study $\left(\varepsilon_{T}=3.99\right)$, observed at Tarzana during the 1987 Whittier Narrows earthquake, for a response period of $0.30 \mathrm{~s}$. Large residuals have also been observed for this record at other response periods, and the record clearly departs from the general pattern observed for ground motions from this event (Shakal et al., 1988). The preliminary analysis concluded that a strong site effect was responsible for the large residuals (Campbell, 1988), which was surprising considering the location of the station on a gently sloping hill, the site being classified as rock; however, the matter was not investigated further until the same site again recorded unusually large ground motions during the 1994 Northridge event. Interpretations of the unusual ground motions observed at Tarzana include topographic amplification by the hill combined with 3D-effects of the underlying geological structure due to the inclination of incident waves (Bouchon and Barker, 1996; Spudich et al., 1996; Vahdani and Wikstrom, 2002), resonant sliding block behaviour induced by a small nearby event triggered by the mainshock (Rial, 1996), and effects of highly saturated layers at shallow depths (Catchings and Lee, 1996). The overall conclusion from these studies is that the strong amplification at Tarzana results from a combination of factors which are specific to this particular site, and its position with respect to regional sources. For these types of records, the issue then becomes to determine how likely it is that a similar combination of effects occurs somewhere else, and in particular at the site of interest for the seismic hazard analysis. For the example of Tarzana, which appears to be an exceptional occurrence, the effects listed above could be irrelevant to a 
site associated with different geological and topographical conditions, e.g., a flat hard-rock site, which would be a typical site condition for critical facilities in stable continental regions such as the Central and Eastern United States, or northwestern Europe.

The 1989 Loma Prieta event contributes 9 records to the selection, all of which are from the San Francisco-Oakland area. The fact that ground motions were higher in the Bay Area compared to locations closer to the source has been related to critical Moho reflections (Somerville and Yoshimura, 1990), combined with forward-directivity effects from a bilateral rupture (Somerville et al., 1994). The selected records constitute only a subset of the Bay Area records, and it is therefore likely that they are affected by additional, more site-specific factors. Explanations include amplification by soft soil sediments (e.g., Borcherdt and Glassmoyer, 1994; Field et al., 1994), relative amplification at rock sites located on less competent materials than the Franciscan Complex (Borcherdt and Glassmover, 1994), topographic effects (Borcherdt and Glassmover, 1994) and possible influence of ocean-wave motions (Vidale and Bonamassa, 1994). These diagnostics are, however, shared with a number of other records included in the NGA dataset used in the regression that do not exhibit large enough residual values to be included in the selection. For example, the arguments put forward to explain the large ground motions recorded at Alameda Naval Air Station and nearby Treasure Island are the same, namely resonant response of the soft Bay sediments underlying the stations. A direct comparison is made possible by the fact that studies investigating the response of these stations (e.g., Carlisle and Rollins, 1994; Borcherdt and Glassmoyer, 1994) use the same reference rock site (Yerba Buena Island). Nevertheless, there are significant differences in residual values, the Alameda record being associated with residuals large enough to be included in the selection, whereas the Treasure Island record is associated with smaller residuals $\left(\varepsilon_{T}=1\right.$ to 1.5$)$ and therefore not included in the selection. This example illustrates the difficulty of establishing a robust relation between causative factors and large residual values even in cases where the records are particularly well documented.

The 1994 Northridge event also falls into this category, contributing records from three stations: Tarzana, Pacoima Dam, and Santa Monica City Hall. Additionally, the Rinaldi Receiving Station record from the March aftershock is selected. The site conditions at Tarzana have already been discussed above. Pacoima Dam is another location well known for its somewhat unusual site configuration, the instrument being located on top of a small ridge, close to the bottom of a canyon and next to a large structure. Possible effects of these factors have been investigated after this site recorded large ground motions during the 1971 San Fernando event (Boore, 1973; Bouchon, 1973; Wong and Jennings, 1975; Reimer et al., 1974; Anooshehpoor and Brune, 1989), but no consensus has been reached, and an influence of the source could not be excluded (e.g., Bouchon, 1978). The occurrence of even larger ground motions at the same site in 1994 despite a location on the footwall (as opposed to the hanging wall of the 1971 event) and at a 
slightly greater distance from the source would tend to favour a site effect interpretation (e.g., Shakal et al., 1996). The ground motions at Santa Monica, which constituted a pocket of high damage, have been related to $3 \mathrm{D}$ basin effects caused by the geological structure associated with the Santa Monica fault forming the northern edge of the Los Angeles Basin. There is, however, disagreement as to whether these large ground motions were caused by deep structural focusing (Gao et al., 1996; Davis et al., 2000) or by shallow-basin-edge-induced surface waves (Graves et al., 1998; Alex and Olsen, 1998).

\section{Category III: Records from events with intermediate sample size}

Events in category III can still be considered reasonably well-recorded, but the records are generally not as well documented as those from category-II events. This can be due to two factors: either the records come from a well-documented event, such as Landers or Kobe, but have received comparatively little attention due to their location far from the source (about 90 and $120 \mathrm{~km}$ for the Landers and Kobe records, respectively), or the event as a whole is not particularly well documented. An example of the latter is the Napa Fire Station record from the 2000 Yountville, California, event. Considering its small-to-moderate size $\left(M_{w} 5.0\right)$, this event caused a significant amount of damage in the Napa Valley ( $\$ 30-50 \mathrm{M}$ of damage, and 25 injured). Preliminary reports (USGS, 2000; Miranda and Aslani, 2000; EERI, 2000) commented on the unusually high level of the ground motions recorded at several stations located in the town of Napa, and tentatively attributed them to the combined effects of forward rupture directivity, topography and surface sediments based on a comparison with ground motions recorded on rock at similar distances. There is, however, little information available beyond this almost circumstantial evidence.

\section{Category IV: Records from events with small sample size}

Records in category IV are generally poorly documented. Most of the records selected from events contributing a small number of records to the regression are selected at long response periods, where the dataset is reduced due to the limitations imposed by the filter cut-off, and also appears to be more balanced (i.e., all events contribute similar numbers of records). The Mammoth Lakes-06 event constitutes an exception, contributing 3 records out of 5 to the largeepsilon selection at high frequencies. Examination of the residuals shows that this event is associated with the highest inter-event residual $\varepsilon_{\mathrm{E}}$ in the dataset at high frequencies, i.e. the selection of the records appears to be event-driven. A possible explanation for this unusual highfrequency behaviour is 'exotic' focusing by scattering features located along the wave path related to the volcanic nature of the surroundings (Peppin, 1987). If this factor is indeed driving the value of the inter-event residual, then it could be argued that the Mammoth Lakes records should be excluded from the regression, since similar path characteristics would not be expected in other tectonic environments. 


\section{Discussion and Conclusions}

The main objective of this study was to determine whether it is possible to identify specific physical mechanisms causing ground motions to deviate significantly from median predictions in order to physically constrain truncation levels. For this purpose, "high- $\varepsilon$ " accelerograms from the Abrahamson and Silva (2005) dataset, defined as those satisfying $\varepsilon_{\mathrm{T}} \geq 2.5$ for at least one of the 15 response periods considered, have been examined on an individual basis. The review of published interpretations for the selected accelerograms, in some cases supplemented by comparisons between the selected data and other records recorded at the same station or during the same event, leads to the identification of a number of source, path and site factors that can be considered at least partially responsible for the deviation from predictions. These include both factors that are not included in the predictive model, such as three-dimensional effects caused by the surface or subsurface topography, and other factors which are included in the model but represented in a manner too crude to fully capture the associated ground-motion variability, such as effects due to a high lateral variability in near-surface geology.

The better-documented examples investigated in this study show that it is difficult to robustly associate large values of $\varepsilon_{\mathrm{T}}$ with particular physical mechanisms. Clear-cut cases such as Tarzana, where a large residual can be attributed with a high level of confidence to site-specific effects, are rare. More commonly, factors pertaining to both the source and the site, and sometimes the path, are required to explain the observed ground-motion behaviour. No example of deviation attributable exclusively to characteristics of the source has been found. Indeed, in one of the two cases where the total residual value was clearly driven by the large value of the inter-event residual (the Mammoth Lakes aftershock), the suggested explanation is more related to the path than to the source. In fact, considering how few records from this event are included in the regression, the large inter-event residual could be a recording bias, ground motions from this event appearing to be higher than usual because only the subset of amplified motions is considered. Thus, a high inter-event residual is not necessarily solely related to source characteristics; conversely, a purely source-related effect observed at a single station (e.g., in the case of a sparse network) might lead to a high intra-event residual. Hence, as long as the unexplained part of the ground motion may be caused simultaneously by source, path and site effects, the interpretation of the observed deviations from the predicted behaviour will remain ambiguous, even when the different components of variability are considered.

There is often controversy amongst published studies regarding the details of the interpretation of specific records, which can be related to the complex nature of the phenomena involved. In particular, physical factors which manifest themselves in an increased variability of the ground motions, and can lead to both amplifications and deamplifications, have been found to be very 
sensitive to assumptions made during the interpretation. In view of the level of controversy surrounding the interpretation of the motions even in a particularly well-documented case such as Santa Monica, it is doubtful that these physical factors can be incorporated into predictive models in the foreseeable future, since the calibration will be even more uncertain in the context of prediction than in the context of back-analysis. If such effects were nonetheless to be incorporated into predictive models in the form of corrective factors to be applied a posteriori to regression results, as has for instance been suggested for rupture directivity (Somerville et al., 1997), then the dataset used in the regression should ideally be exempt of records that are influenced by these effects. Including such records in the regression and subsequently applying an independently-derived correction factor without adjusting the intra-event variability $\left(\sigma_{A}\right)$ appropriately will result in over-estimating the effect of the physical process under consideration, which will be reflected both in the value of the variability (to which the effect contributes since it is unexplained by the ground-motion model used in regression) and the scaling of the ground motion (which assumes the value predicted by the regression is totally unaffected by this physical process). The procedure of reducing $\sigma_{\mathrm{A}}$ when a directivity correction is applied is explained in Abrahamson (2000b).

A robust relation between specific physical mechanisms and large residual values has been difficult to establish even when a certain degree of consensus is reached as to the causative physical factors. For instance, the deviation from predictions for several of the Loma Prieta records is attributed to the response of surface deposits which are too complex to be captured by the $V_{\mathrm{S}, 30}$-based representation of the site conditions in the predictive model. Records from sites exhibiting the same characteristics and for which a similar interpretation is suggested can, however, be found elsewhere in the dataset, associated with much lower residual values. The implication of this is that if the high- $\varepsilon$ record is eliminated on the basis of the causative physical mechanism, so should lower- $\varepsilon$ records sharing the same interpretation, as well as low- $\varepsilon$ records whose deviation can be related to the same process (e.g., backward directivity). This, however, requires the documentation of the whole dataset, rather than a small subset of outlying records, and thus negates the purpose of a detection method based on the value of the residual, whose goal is precisely to limit investigations to a few records. More importantly, it would indicate that the diagnosis is either wrong (the large value of $\varepsilon$ is not related to this particular physical process), incomplete (the large value of $\varepsilon$ is not solely related to this particular physical process) or too crude (the large value of $\varepsilon$ can be fully explained by this particular physical process, but the predictive model does not capture the variability associated with the process). The only explanations that would definitely allow rejection of records as "discordant outliers" are those involving mechanisms such as contamination by foundations or nearby structures, which would justify the exclusion of the record from a dataset used for the prediction of free-field ground motions. However, as mentioned previously, such records would usually have been excluded 
from the dataset prior to regression, and therefore it would seem that there is not much to be gained from examining high- $\varepsilon$ records once the regression analysis has been carried out.

Furthermore, there are intrinsic limitations to a selection criterion based on a fixed threshold value for the total normalised residual $\left(\varepsilon_{T}\right)$, rather than a more sophisticated criterion considering the values of $\varepsilon_{\mathrm{E}}$ and $\varepsilon_{\mathrm{A}}$ separately. Although $\varepsilon_{\mathrm{T}}$ is the variable most commonly used for seismic hazard analysis, it masks the relative contributions of inter-event variability $\left(\sigma_{E}\right)$ and intra-event variability $\left(\sigma_{A}\right)$, which may contain indications on the origin of the deviation from predictions (source-driven or site-specific). This information can be retrieved for a given record by comparing the values of the inter-event and intra-event residuals, $\varepsilon_{\mathrm{E}}$ and $\varepsilon_{\mathrm{A}}$. This interpretation may, however, be blurred by path-related effects, which will impact more strongly on one or other of these variables, depending on the spatial sampling of the records. General conclusions are also affected by the fact that the interpretation of the inter-event variability may be influenced by the number of records from the event used in the regression. Therefore, the accelerograms examined in the present study have been grouped into four categories, depending on the amount of data contributed to the regression by the causative event. This grouping scheme also highlights the fact that the level of documentation of any given event is critically dependent on the quantity and quality of data available from this event. If there are not enough good quality observations available, as is often the case for older and smaller events, no definitive conclusions can be reached. On the other hand, the example of the Chi-Chi sequence clearly shows that when events trigger large numbers of instruments, interpretations of individual records or stations are difficult to find.

It is worth noting that the amount of attention bestowed on specific records is by no means an indication of their potential usefulness to ground-motion estimation as a general problem. For instance, the Pacoima Dam site is in all likelihood one of the best-documented strong-motion recording sites; it is, however, doubtful that similar conditions are reproduced elsewhere, and in particular at a site selected for the location of a nuclear facility critical enough to raise the issue of truncation. Conversely, damaging motions from small-to-moderate events (M 6), such as Yountville, are generally not studied in great depth. Given the potential relevance of such events to the estimation of ground motions in stable continental regions, where the hazard is typically dominated by near-source ground motions from similar-sized events, these motions could therefore be more worthwhile investigating than ground motions recorded under particular and unusual conditions.

The main conclusion of the present study is that it is not currently possible to obtain a direct physical constraint on the level at which the ground-motion distribution associated with an empirical predictive equation should be truncated. Although some of the records associated with high values of $\varepsilon_{T}$ are clearly affected by physical processes that could be discounted in a design 
situation (e.g., basin-edge effects, topographical amplification by a ridge) and would therefore not be used as input motions for design, the removal of such records from the dataset used in the derivation of empirical predictive equations is debatable. Indeed, the largest values of residuals found in the present study can only be related to specific physical processes inasmuch as the relevant parameters are documented, which is often not the case. Furthermore, the level of controversy that exists regarding the back-analysis of particularly well-documented examples such as Santa Monica does not bode well for establishing a correlation in a forward-modelling context, as would be required for prediction purposes. The implication of this is that in the shortterm, the choice of the truncation level to be used in seismic hazard analysis remains a matter of subjective judgment, which should be based on probability (Table 1). The good fit to the lognormal distribution observed for more recent predictive models based on larger datasets and more sophisticated models is encouraging, as it provides a sound statistical basis for the use of the lognormal assumption.

It should also be noted that a uniform truncation at a predefined number of standard deviations, while intuitively appealing because of its simplicity, is not without practical limitations. Firstly, the values of $\varepsilon$ associated with specific accelerograms are likely to change over time, since they are coupled with the value of the (apparent) aleatory variability, which is likely as site-source-specific ground-motion models are developed (e.g. Atkinson, 2006). More importantly, the coupling between $\varepsilon$ and $\sigma$ causes the truncation level in terms of absolute ground motion to be dependent on the predictive equation used. This is likely to be a problem for the practical implementation of the truncation scheme, since projects that are critical enough to raise the issue of truncation in the first place are expected to include more than one predictive equation through a logic-tree formulation (Bommer et al., 2005). The increased availability of strong-motion data from dense networks is likely to lead to improved constraints on the individual components of variability, as well as allowing the use of better-behaved (e.g., less unbalanced) datasets. Therefore, further investigations into the nature of $\sigma$ ultimately appear more promising than the quest for the 'right' $\varepsilon_{\max }$

An alternative approach would be to define thresholds on absolute ground-motion levels and translate these cut-offs into equation-specific $\varepsilon_{\max }$ values, under the assumption that the upper bound curves follow a shape similar to that of the median curves. This would solve the issue of compatibility of the truncation levels between different equations. Such an approach is, however, unlikely to be less arbitrary than a uniform $\varepsilon_{\max }$ truncation in the near future. Indeed, although there are theoretical arguments mainly related to energy conservation and finite material strength to justify the existence of constraints on the amplitude of ground motion (Bommer et al., 2004), the perception of what can be considered to be an appropriate limiting value has been shown to be strongly influenced by the values of ground motions instrumentally recorded to date. This was observed by the experts addressing the issue of maximum ground motions on rock in the 
PEGASOS project, who favoured an estimation in terms of absolute levels of ground motion, rather than $\varepsilon_{\max }$, to avoid equation-specific cut-offs in the hazard calculations (Bommer, 2004). Numerical simulations from advanced seismological models could provide insights into the expected nature of the upper tail of the ground-motion distribution, but are currently lacking sufficient constraints on the joint distributions of source parameters used in the model

\section{Acknowledgements}

This work was partly funded by the Electric Power Research Institute (EPRI Agreement EPP17705/C8717) and by the PG\&E/DOE cooperative agreement on "Development and Verification of an Improved Model for Extreme Ground Motions Produced by Earthquakes" (DOE Award Number DE-FC28-05RW12358). In this context, the study has greatly benefited from discussions with Stephen Day, Robert Graves, Martin Mai, Carl Stepp, Jonathan Stewart and Robert Youngs, whose comments and insights are gratefully acknowledged. We would also like to express our thanks to Paul Somerville and an anonymous reviewer, whose careful review and insightful comments have contributed to significantly improve the present paper, and to Peter Stafford, for his very thorough review of an early version of the manuscript.

\section{References}

Abrahamson, N.A. (2000a). State of the practice of seismic hazard evaluation. In: Proceedings of GeoEng 2000, Melbourne, 19-24 November, Vol. 1, 659-685.

Abrahamson, N.A. (2000b). Effects of rupture directivity on probabilistic seismic hazard analysis. In: Proceedings of the $6^{\text {th }}$ International Conference on Seismic Zonation, Palm Springs, California, Vol. 1, 151-156.

Abrahamson, N.A., and R.B. Darragh (1985). The Morgan Hill earthquake of April 24, 1984 - The $1.29 \mathrm{~g}$ acceleration at Coyote Lake Dam: Due to directivity, a double event, or both? Earthq Spectra 1(3):445-455.

Abrahamson, N.A., and K.M. Shedlock (1997). Overview. Seism Res Lett 68(1): 9-23.

Abrahamson, N.A., and W.J. Silva (1997). Empirical response spectral attenuation relations for shallow crustal earthquakes. Seism Res Lett 68(1):94-127.

Abrahamson, N.A., and W. Silva (2005). Datafiles of preliminary ground-motion model prepared for the PEER/NGA project, April 2005.

Abrahamson, N.A., and W. Silva (2007). Abrahamson \& Silva NGA ground motion relations for the geometric mean horizontal component of peak and spectral ground motion parameters. Version 1, June 2007. Available from http://peer.berkeley.edu/lifelines/repngamodels.html 
Abrahamson, N.A., and R.R. Youngs (1992). A stable algorithm for regression analysis using the random effects model. Bull Seismol Soc Am 88(1):505-510.

Abrahamson, N.A., P. Birkhauser, M. Koller, D. Mayer-Rosa, P. Smit, C. Sprecher, S. Tinic, and R. Graf (2002). PEGASOS - a comprehensive probabilistic seismic hazard assessment for nuclear power plants in Switzerland. In: Proceedings of the 12th European Conference on Earthquake Engineering, London, Paper No. 633.

Alex, C.M., and K.B. Olsen (1998). Lens-effect in Santa Monica? Geoph Res Lett 25(18):34413444.

Ambraseys, N.N., J. Douglas, S.K. Sarma, and P.M. Smit (2005). Equations for the estimation of strong ground motions from shallow crustal earthquakes using data from Europe and the Middle East: Horizontal peak ground acceleration and spectral acceleration. Bull Earthq Eng 3(1):1-53.

Ambraseys, N.N., K.A. Simpson, and J.J. Bommer (1996). Prediction of horizontal response spectra in Europe. Earthq Eng Struct Dyn 25(4):371-400.

Anderson, J.G., and J.N. Brune (1999). Probabilistic seismic hazard assessment without the ergodic assumption. Seismol Res Lett 70(1):19-28.

Anooshehpoor, A., and J.N. Brune (1989). Foam rubber modeling of topographic and dam interaction effects at Pacoima Dam. Bull Seismol Soc Am 79(5):1347-1360.

Atkinson, G. M. (2006). Single-station sigma. Bull Seismol Soc Am 96(2):446-455.

Barnett, V., and T. Lewis (1994). Outliers in statistical data (3rd Edition). John Wiley and Sons, Chichester, $584 \mathrm{pp}$.

Barnett, V., and D. Roberts (1993). The problem of outlier tests in sample surveys. Comm. in Statistics - Theory and Methods 22. [not seen; quoted in Barnett and Lewis (1994)]

Bazzurro, P., and C.A. Cornell (1999). Disaggregation of seismic hazard. Bull Seismol Soc Am 89(2):501-520.

Berge-Thierry, C., F. Cotton, O. Scotti, D.-A. Griot-Pommera, and Y. Fukushima (2003). New empirical response spectral attenuation laws for moderate European earthquakes. J Earthq Eng 7(2):193-222.

Bernreuter, D.L., J.B. Savy, R.W. Mensing, and J.C. Chen (1989). Seismic hazard characterization of 69 nuclear power plant sites East of the Rocky Mountains. US Nuclear Regulatory Commission Report NUREG/CR-5250.

Beyer, K., and J. J. Bommer (2006). Relationships between median values and between aleatory variabilities for different definitions of the horizontal component of motion. Bull Seismol Soc Am 96(4):1512-1522.

Bezdek, J. C., and K.H. Solomon (1983). Upper limit lognormal distribution for drop size data. ASCE J Irr Drainage Eng 109(1):72-88.

Bommer, J.J. (2002). Deterministic vs. probabilistic seismic hazard assessment: an exaggerated and obstructive dichotomy. J Earthqu Eng 6(Special Issue 1):43-73.

Bommer, J.J. (2004). The use of empirical data, numerical simulation and expert judgment to define upper bounds on ground motions: Insights from the PEGASOS project. In: Proceedings of Workshop on Extreme Ground Motions at Yucca Mountain, Menlo Park, California, August 2004.

Bommer, J.J. (2006). Re-thinking seismic hazard mapping and design return periods. In: Proceedings $1^{\text {st }}$ ECEES, Geneva, Paper No. 1304.

Bommer, J.J., and N.A. Abrahamson (2006). Why do modern probabilistic seismic-hazard analyses often lead to increased hazard estimates? Bull Seismol Soc Am 96(6):1967-1977. 
Bommer, J.J., N.A. Abrahamson, F.O. Strasser, A. Pecker, P.-Y. Bard, H. Bungum, F. Cotton, D. Fäh, F. Sabetta, F. Scherbaum, and J. Studer (2004). The challenge of defining upper bounds on earthquake ground motions. Seismol Res Lett 75(1):82-95.

Bommer, J.J., J. Douglas, and F.O. Strasser (2003). Style-of-faulting in ground-motion prediction equations. Bull Earthq Eng 1(2):171-203.

Bommer, J.J., G.G. Georgallides, and I.J. Tromans (2001). Is there a near-field for small-tomoderate magnitude earthquakes? J Earthq Eng 5(3): 395-423.

Bommer, J., F. Scherbaum, H. Bungum, F. Cotton, F. Sabetta, and N. Abrahamson (2005). On the use of logic-trees for ground-motion prediction equations in seismic-hazard analysis. Bull Seismol Soc Am 95(2):377-389.

Boore, D.M. (1973). The effect of simple topography on seismic waves: Implications for the accelerations recorded at Pacoima Dam, San Fernando Valley, California. Bull Seismol Soc Am 63(5):1603-1609.

Boore, D.M. (2001). Comparisons of ground motions from the 1999 Chi-Chi earthquake with empirical predictions largely based on data from California. Bull Seismol Soc Am 91(5):12121217.

Boore, D.M., and G.M. Atkinson (2006). Boore-Atkinson provisional NGA empirical ground-motion model for the average horizontal component of PGS, PGV and SA at spectral periods of 0.05 , $0.1, \quad 0.2, \quad 0.3,0.5,1,2,3,4$, and 5 seconds, v1.7. Available from http://peer.berkeley.edu/lifelines/repngamodels.html

Boore, D.M., V.M. Graizer, J.C. Tinsley, and A.F. Shakal (2004). A study of possible groundmotion amplification at the Coyote Lake Dam, California. Bull Seismol Soc Am 94(4):1327-1342.

Boore, D.M., J. Watson-Lamprey, and N.A. Abrahamson (2006). GMRotD and GMRotl: Orientation-independent measures of ground motion. Bull Seismol Soc Am 96(4A):1502-1511.

Borcherdt, R.D., and G. Glassmoyer (1994). Influences of local geology on strong and weak ground motions recorded in the San Francisco Bay region and their implications for site-specific building-code provisions. In: Borcherdt, R.D. (ed.). The Loma Prieta, California, Earthquake of October 17, 1989 - Strong Ground Motion. U.S. Geol. Survey Prof. Paper 1551-A:77-108.

Bouchon, M. (1973). Effect of topography on surface motion. Bull Seismol Soc Am 72(3):615-632.

Bouchon, M. (1978). A dynamic source model for the San Fernando earthquake. Bull Seismol Soc Am 68(6):1555-1576.

Bouchon, M., and J.S. Barker (1996). Seismic response of a hill: The example of Tarzana, California. Bull Seismol Soc Am 86(1): 66-72.

Campbell, K.W. (1988). The Whittier Narrows, California earthquake of October 1, 1987 Preliminary analysis of peak horizontal acceleration. Earthq Spectra 4(1):115-137.

Campbell, K.W., and Y. Bozorgnia (2006). Campbell-Bozorgnia NGA empirical ground motion model for the average horizontal component of PGA, PGV, PGD and SA at selected spectral periods ranging from $0.01-10.0$ seconds (Version 1.0). Available from http://peer.berkeley.edu/lifelines/repngamodels.html

Carlisle, H., and K.M. Rollins (1994). Ground-response studies at the Alameda Naval Air Station. In: Borcherdt, R.D. (ed.). The Loma Prieta, California, Earthquake of October 17, 1989 - Strong Ground Motion. U.S. Geol. Survey Prof. Paper 1551-A: 123-143.

Catchings, R.D., and W.H.K. Lee (1996). Shallow velocity structure and Poisson's ratio at the Tarzana, California, strong-motion accelerometer site. Bull Seismol Soc Am 86(6):1704-1713.

Chang, T.-Y., F. Cotton, and J. Angelier (2001). Seismic attenuation and peak ground acceleration in Taiwan. Bull Seismol Soc Am 91(5):1229-1246. 
Chen, K.-C., B.-S. Huang, J.-H. Wang, and J.-H. Yen (2002). Conjugate thrust faulting associated with the 1999 Chi-Chi, Taiwan, earthquake sequence. Geoph Res Lett 29(8), Art. No. 1277.

Chen, Y. H., and C. C. P. Tsai (2002). A new method for estimation of the attenuation relationship with variance components. Bull Seismol Soc Am 92(5):1984-1991.

Chi, W.-C., and D. Dreger (2004). Crustal deformation in Taiwan: Results from finite source inversions of six Mw > 5.8 Chi-Chi aftershocks. J Geoph Res 109(7), Art. No. B07305.

Chiou, B. S.-J., and R.R. Youngs (2006). Chiou and Youngs PEER-NGA empirical ground motion model for the average horizontal component of peak acceleration and pseudo-spectral acceleration for spectral periods of 0.01 to 10 seconds, interim report for USGS review. Available from http://peer.berkeley.edu/lifelines/repngamodels.html

Davis, P.M., J.L Rubinstein, K.H. Liu, S.S. Gao, and L. Knopoff (2000). Northridge earthquake damage caused by geologic focusing of seismic waves. Science 289:1746-1750.

Douglas, J. (2003a). Earthquake ground motion estimation using strong-motion records: a review of equations for the estimation of peak ground acceleration and response spectral ordinates. Earth Sci Rev 61: 43-104.

Douglas, J. (2003b) What is a poor quality strong-motion record? Bull Earthq Eng 1(1):141-156.

Douglas, J., and P.M. Smit (2001). How accurate can strong ground motion attenuation relations be? Bull Seismol Soc Am 91(6):1917-1923.

Draper, N.R., and H. Smith (1981). Applied Regression Analysis. Second Edition, Wiley, New York.

EERI (2000). The Napa earthquake of September 3, 2000. EERI Special Earthquake Report, November 2000. http://www.eeri.org/lfe/pdf/usa_napa_eeri_preliminary_report.pdf

Field, E.H., S.E. Hough, K.H. Jacob, and P.A. Friberg (1994). Site response in Oakland, California, near the failed section of the Nimitz Freeway. In: Borcherdt, R.D. (ed.), The Loma Prieta, California, Earthquake of October 17, 1989 - Strong Ground Motion. U.S. Geol. Survey Prof. Paper 1551-A:169-180.

Gao, S., H. Liu, P.M. Davis, and L. Knopoff (1996). Localized amplification of seismic waves and correlation with damage due to the Northridge earthquake: evidence for focusing in Santa Monica. Bull Seismol Soc Am 86(1B):S209-S230.

Graves, R.W., A. Pitarka, and P.G. Somerville (1998). Ground-motion amplification in the Santa Monica area: effects of shallow basin-edge structure. Bull Seismol Soc Am 88(5):1224-1242.

Hawkins, D.M. (1980). Identification of outliers. Chapman and Hall, London, 188pp.

Kagawa, T., K. Irikura, and P.G. Somerville (2004). Differences in ground motion and fault rupture process between the surface and buried rupture earthquakes. Earth Planets Space 56(1): 3-14.

Kao, H., Y.-H. Liu, W.-T. Liang, and W.-P. Chen (2002). Source parameters of regional earthquakes in Taiwan:1999-2000 including the Chi-Chi earthquake sequence. TAO 13(3):279298.

Krinitzsky, E.L. (2002). How to obtain ground motions for engineering design. Eng Geol 65(1):116.

Lee, C-T., C.T. Cheng, C.W. Liao, and Y.B. Tsai (2001). Site classification of Taiwan free-field strong-motion stations. Bull Seismol Soc Am 91(5):1283-1297.

Lussou, P., P.Y. Bard, and F. Cotton (2001). Seismic design regulation codes: Contribution of KNet data to site effect evaluation. J Earthq Eng 5(1):13-33.

Marin, S., J.P. Avouac, M. Nicolas, and A. Schlupp (2004). A probabilistic approach to seismic hazard in metropolitan France. Bull Seismol Soc Am 94(6):2137-2163. 
Martínez-Pereira, A., and Bommer, J. J. (1998). What is the near-field? In: Booth, E. (ed.) Seismic Design Practice into the Next Century, Balkema, pp. 245-252.

McGuire, R.K. (1976). FORTRAN computer program for seismic risk analysis. U.S. Geol. Survey Open-File Report 76-67.

Miranda, E., and H. Aslani (2000). Brief Report on the September 3, 2000 Yountville/Napa California Earthquake. Report prepared for the Pacific Earthquake Engineering Center. http://nisee.berkeley.edu/yountville/

PEER (2005). Documentation on the Next Generation Attenuation of Ground Motions (NGA) Project. http://peer.berkeley.edu/lifelines/nga.html and http://peer.berkeley.edu/nga/index.html

Peppin, W.A. (1987). Exotic seismic phases recorded near Mammoth Lakes and their use in the delineation of shallow-crustal (magma) anomalies. Pageophys 125(6):1008-1023.

Rial, J. A. (1996). The anomalous seismic response of the ground at the Tarzana Hill site during the Northridge 1994 southern California earthquake: a resonant, sliding block? Bull Seismol Soc Am 86(6):1714-1723.

Reimer, R.B., R.W. Clough, and. J.M. Raphael (1974). Seismic response of Pacoima Dam in the San Fernando earthquake. In: Proceedings of the Fifth World Conference on Earthquake Engineering, Rome, Vol. 2:2328-2337.

Restrepo-Vélez, L.F., and J.J. Bommer (2003). An exploration of the nature of the scatter in ground-motion prediction equations and the implications for seismic hazard assessment. J Earthq Eng 7(Special Issue 1):171-199.

Romeo, R., and A. Prestininzi (2000). Probabilistic versus deterministic hazard analysis: an integrated approach for siting problems. Soil Dyn Earthq Eng 20(1-4):75-84.

Seno, T.,K. Otsuki, and C.N. Yang (2000). The1999 Chi-Chi, Taiwan, earthquake: a subduction zone earthquake on land. Bull Earthq Res Inst 75:57-77.

Shakal, A., M.J. Huang, and T.Q. Cao (1988). The Whittier Narrows, California, earthquake of October 1, 1987 - CSMIP strong motion data. Earthq Spectra 4(1):75-100.

Shakal, A.F., M.J. Huang, and R.B. Darragh (1996). Interpretation of significant ground-response and structure strong motions recorded during the 1994 Northridge earthquake. Bull Seismol Soc Am 86(1B):S231-S246.

Somerville, P., and J. Yoshimura (1990). The influence of critical Moho reflections on strong ground motions recorded in San Francisco and Oakland during the 1989 Loma Prieta earthquake. Geoph Res Lett 17(8):1203-206.

Somerville, P.G., N.F. Smith, and R.G. Graves (1994). Effect of critical reflections from the Moho on the attenuation of strong ground motion. In: Borcherdt, R.D. (ed.). The Loma Prieta, California, Earthquake of October 17, 1989 - Strong Ground Motion. U.S. Geol. Survey Prof. Paper 1551A:67-76.

Somerville, P.G., N.F. Smith, R.W. Graves, and N.A. Abrahamson (1997). Modification of empirical strong ground motion attenuation relations to include the amplitude and duration effects of rupture directivity. Seism Res Lett 68(1):199-222.

Spudich, P., M. Hellweg, and W.H.K. Lee (1996). Directional topographic site response at Tarzana observed in aftershocks of the 1994 Northridge, California, earthquake: Implications for mainshock motions, Bull Seismol Soc Am 86(1B):S193-S208.

Stepp, J.C., I. Wong, J. Whitney, R. Quittemeyer, N. Abrahamson, G. Toro, R. Youngs, K. Coppersmith, J. Savy, T. Sullivan, and Yucca Mountain PSHA project members (2001). Probabilistic seismic hazard analyses for ground motions and fault displacements at Yucca Mountain, Nevada. Earthq Spectra 17(1):113-151. 
Strasser, F.O., and Bommer, J.J. (2004). Outliers in strong-motion datasets. In: Proceedings of Workshop on Extreme Ground Motions at Yucca Mountain, Menlo Park, California, August 2004.

Strasser, F.O., and Bommer, J.J. (2005). Large positive ground-motion residuals in the NGA/PEER database. Research Report 05-001-SM, Department of Civil and Environmental Engineering, Imperial College London. Available online at: http://www.imperial.ac.uk/civilengineering/research/researchnewsandreports/researchreports/

USGS (2000). The September 3, 2000 Yountville Earthquake, U.S. Geological Survey, Earthquake Hazards Program online Report (last modified 7/12/2000).

Vahdani, S., and S. Wikstrom (2002). Response of the Tarzana strong motion site during the 1994 Northridge earthquake. Soil Dyn Earthq Eng 22(9-12):837-848.

Vidale, J.E., and O. Bonamassa (1994). Influence of near-surface geology on the direction of ground motion above a frequency of $1 \mathrm{~Hz}$. In: Borcherdt, R.D. (ed.). The Loma Prieta, California, Earthquake of October 17, 1989 - Strong Ground Motion. U.S. Geol. Survey Prof. Paper 1551A:61-66.

Wang, G.-Q., D.M. Boore, H. Igel, and X.-Y. Zhou (2004). Comparisons of ground motions from five aftershocks of the 1999 Chi-Chi, Taiwan, earthquake with empirical predictions largely based on data from California. Bull Seismol Soc Am 94(6):2198-2212.

Wen, K.-L., H.-Y. Peng, Y.B. Tsai, and K.C. Chen (2001). Why 1G was recorded at TCU129 site during the 1999 Chi-Chi, Taiwan, earthquake. Bull Seismol Soc Am 91(5):1255-1266.

Wong, H.L., and P.C. Jennings (1975). Effects of canyon topography on strong ground motion. Bull Seismol Soc Am 65(5), 1239-1257.

Zemell, S.H. (1984). Imposed upper limit for probabilistic seismic risk. In: Proceedings of the 8th World Conference on Earthquake Engineering, Vol. I:239-245. 
Figures 
Figure 1: Influence of truncation level $\varepsilon_{\max }$ on seismic hazard curves (Bommer et al., 2004).

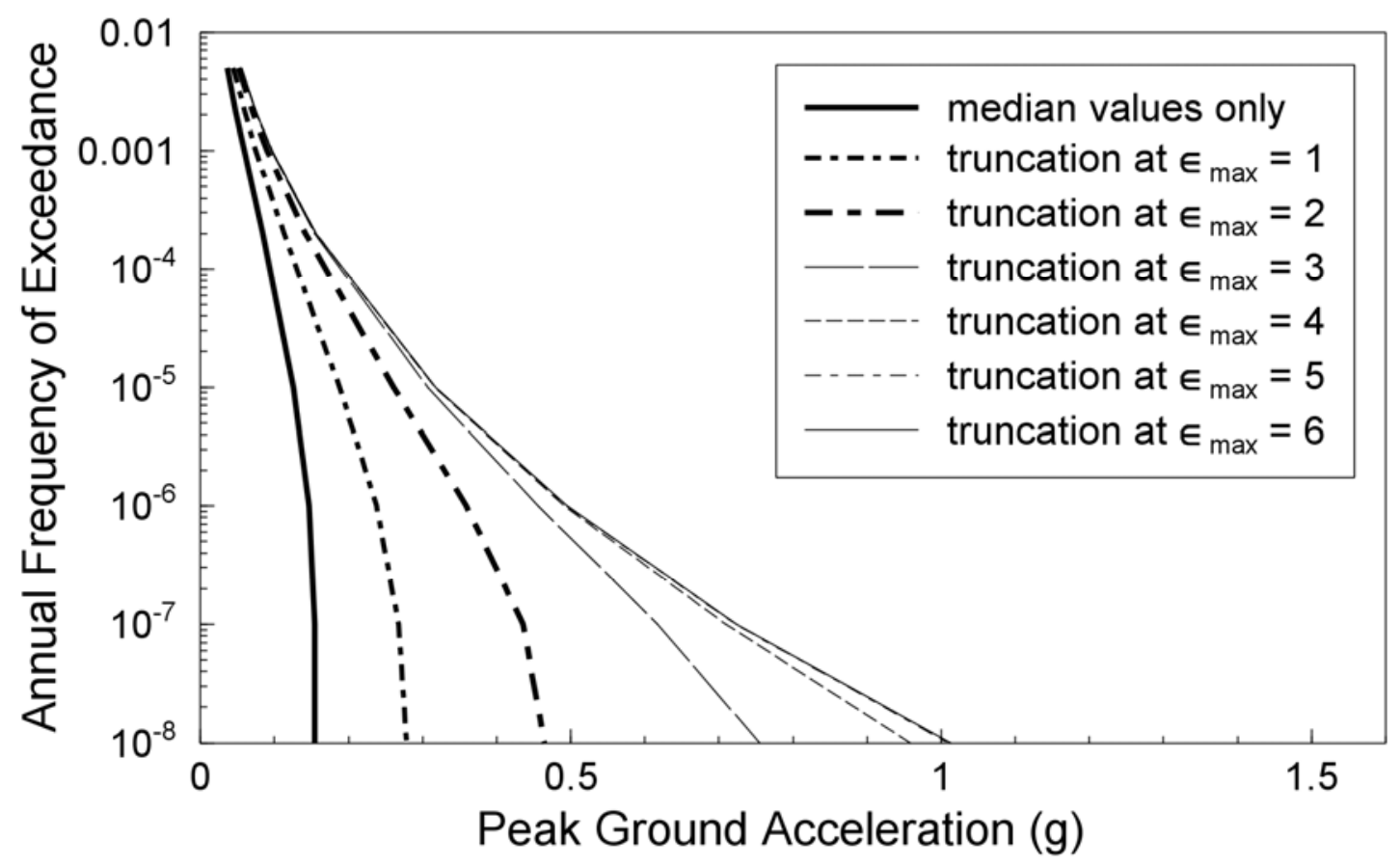


Figure 2: Quantile-quantile plots of the total normalised PGA residuals of the Abrahamson and Silva (2005) model (upper left), and random samples with the same number of points drawn from an untruncated normal distribution (upper right), a normal distribution truncated at $\varepsilon_{\max }=2.5$ (lower left) and at $\varepsilon_{\max }=3.0$ (lower right). If the distribution of the data is normal, the plot will be linear. Superimposed on the plot is a line joining the first and third quartiles of each distribution, extrapolated out to the ends of the sample. The grey-shaded zones at the top and bottom of the plots correspond to sample quantiles outside the range defined by the maximum value of the normalised residual that could be observed for a sample of this size if the residuals were normally distributed $\left(\varepsilon_{\text {max }}^{*}\right)$.

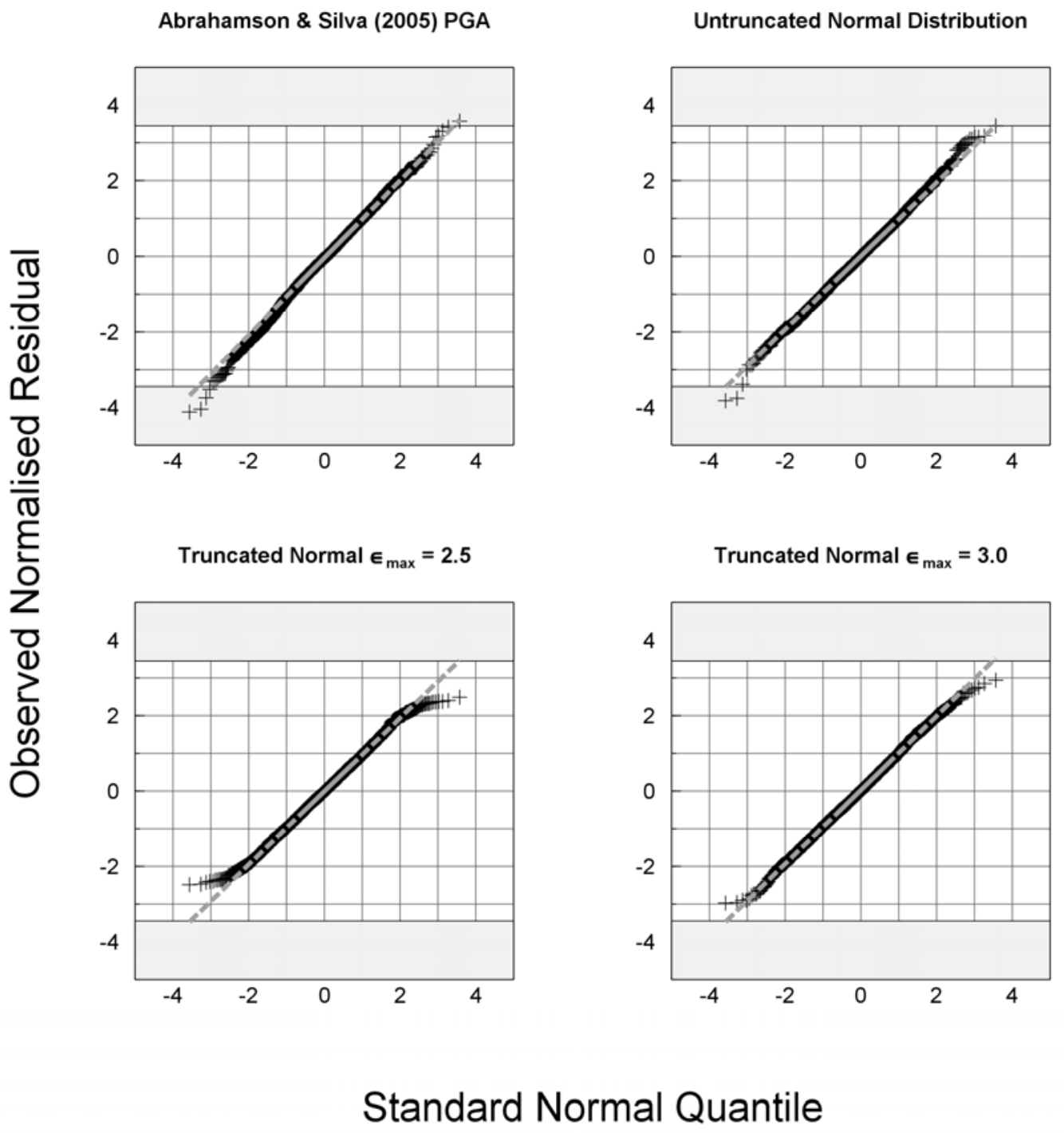


Figure 3: Relation between sample size $\left(N_{P T S}\right)$ and the maximum value of the normalised residual $\left(\varepsilon_{\text {max }}^{*}\right)$ that could be observed if the residuals were normally distributed. The $\varepsilon_{\text {max }}^{*}$ values corresponding to the number of events and records in the Abrahamson and Silva (2005) model used in this study are shown for subsequent reference, for all response periods considered.

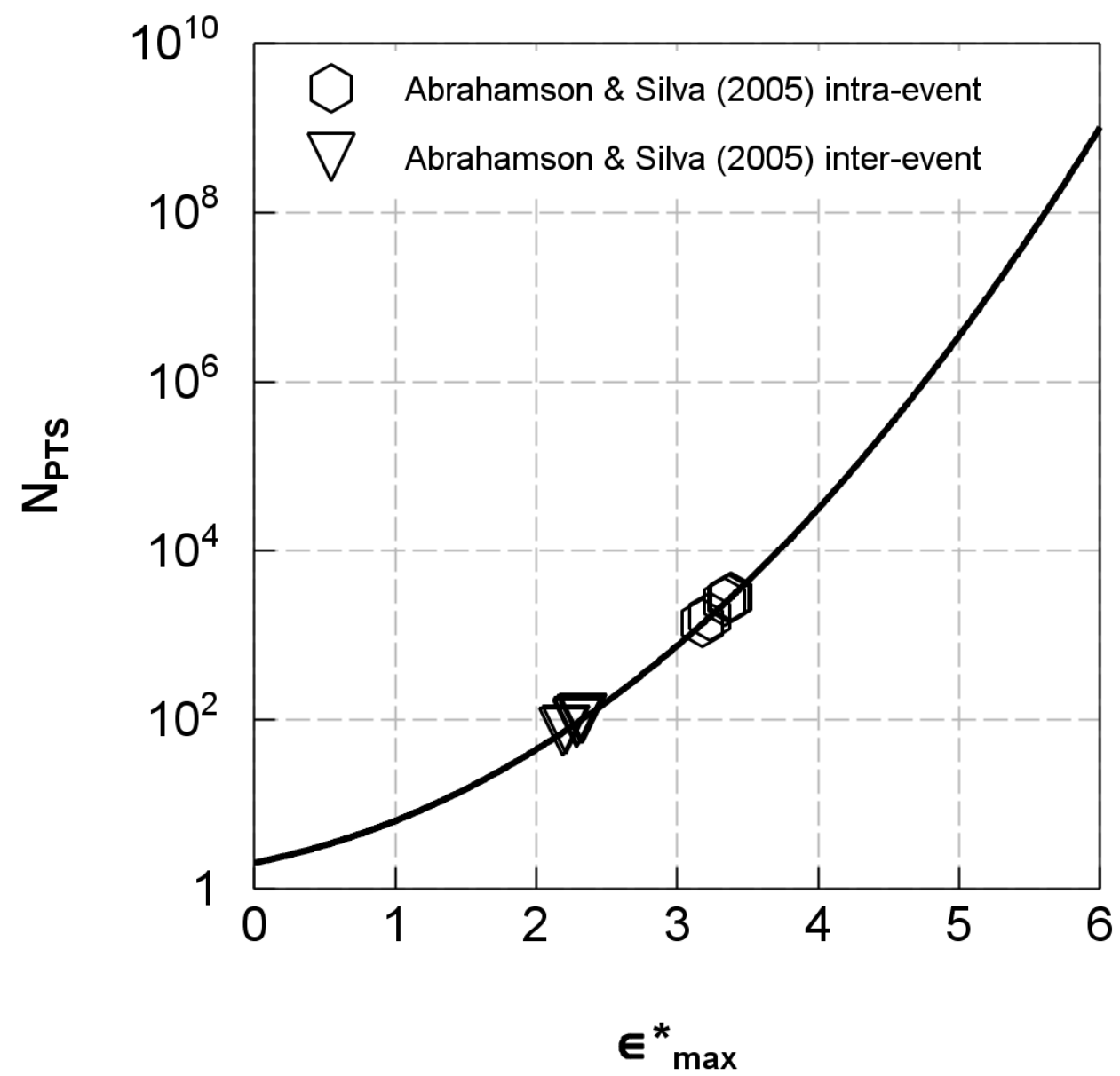


Figure 4: Location with respect to whole dataset of records contributing the 15 highest residuals (numbered squares) for the PGA equation of Bommer et al. (2003). The dashed heavy line corresponds to the approximate boundary of potentially damaging motions inferred by Bommer et al. (2001) based on Martínez-Pereira and Bommer (1998). $R_{J B}$ is the closest distance to the vertical projection of the surface rupture, or Joyner-Boore distance (e.g. Abrahamson and Shedlock, 1997).
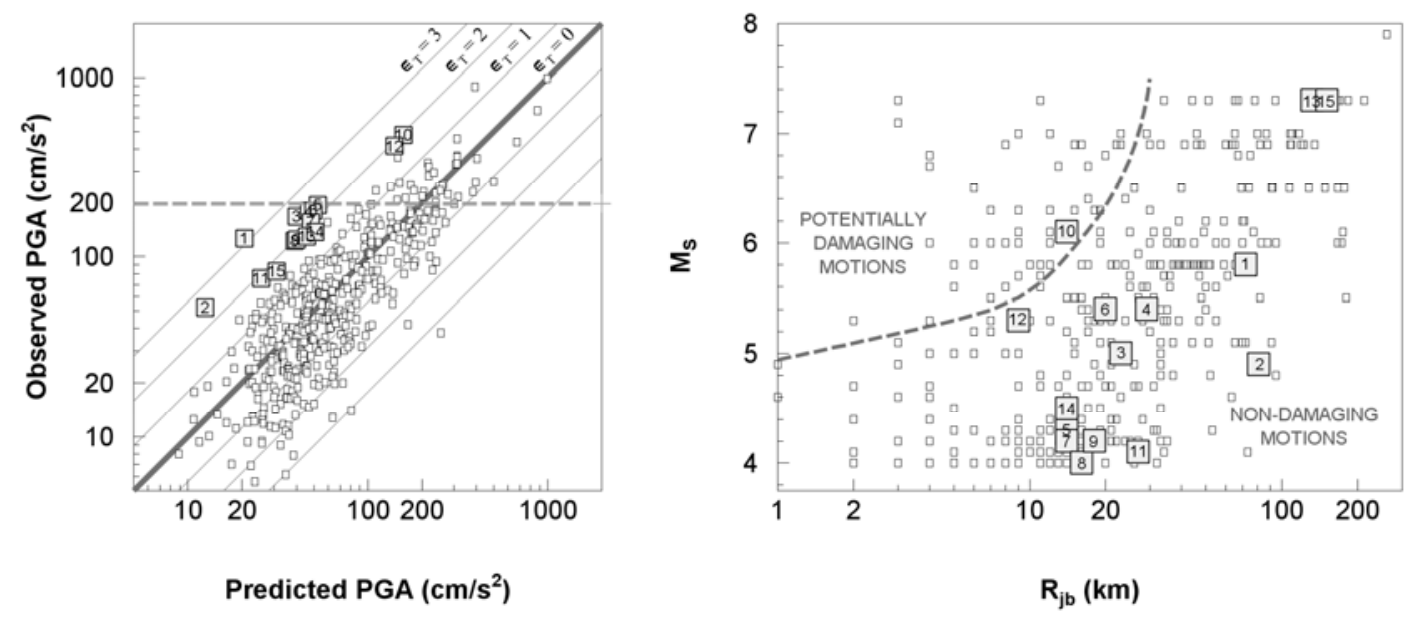
Figure 5: Comparison of total normalised residual $\left(\varepsilon_{T}\right)$ values calculated using the Abrahamson and Silva (2007), Boore and Atkinson, 2006; Chiou and Youngs, 2006 and Campbell and Bozorgnia, 2006) equations with the $\varepsilon_{\mathrm{T}}$ values from the Abrahamson and Silva (2005) model (AS05), for the accelerograms in the high- $\varepsilon_{\mathrm{T}}$ selection. The $\varepsilon_{\mathrm{T}}=2.5$ threshold is indicated by dashed lines. Grey symbols correspond to records from the 1999 Chi-Chi, Taiwan, sequence.

$\begin{array}{ll}\diamond & \text { Ambraseys \& Silva (2007) } \\ 0 & \text { Boore \& Atkinson (2006) } \\ \square & \text { Campbell \& Bozorgnia (2006) } \\ \Delta & \text { Chiou \& Youngs (2006) }\end{array}$

$\mathrm{SA}$ at $0.02 \mathrm{~s}$

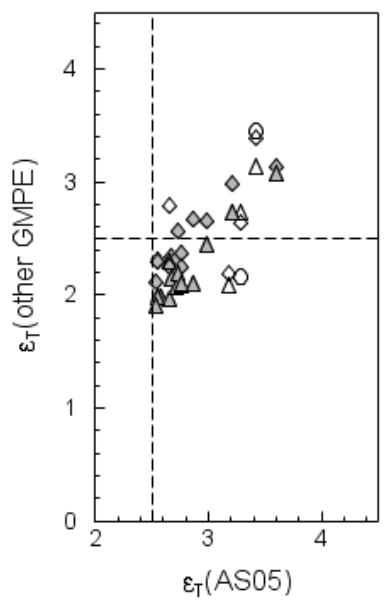

$\mathrm{SA}$ at $0.5 \mathrm{~s}$

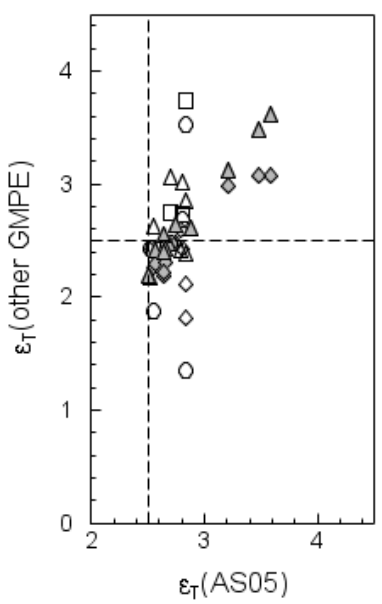

$\mathrm{SA}$ at $0.1 \mathrm{~s}$

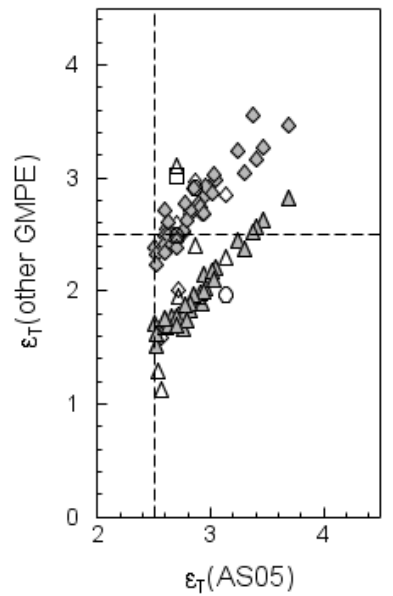

$\mathrm{SA}$ at $0.75 \mathrm{~s}$

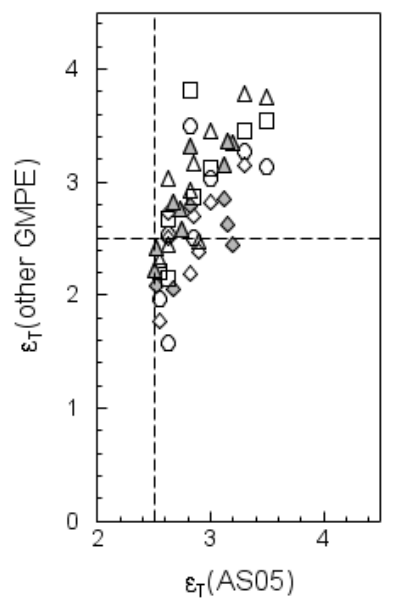

$\mathrm{SA}$ at $0.3 \mathrm{~s}$

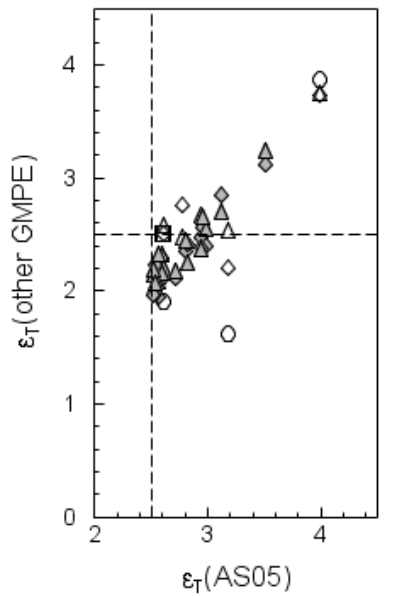

$\mathrm{SA}$ at $1.5 \mathrm{~s}$

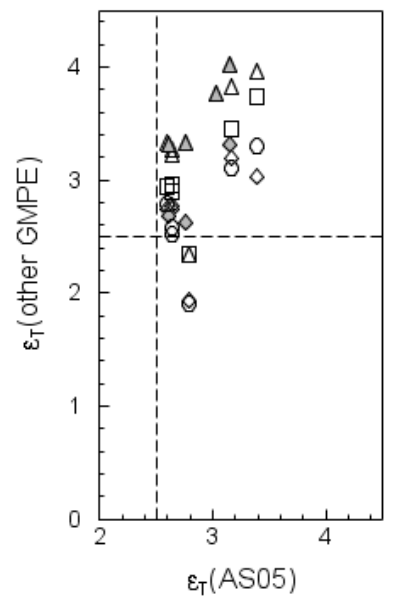


Figure 6: Values of total, inter-event and intra-event variability associated with the Abrahamson and Silva (2005) ground-motion model. The dashed lines correspond to the standard errors of the estimators of the variance components.

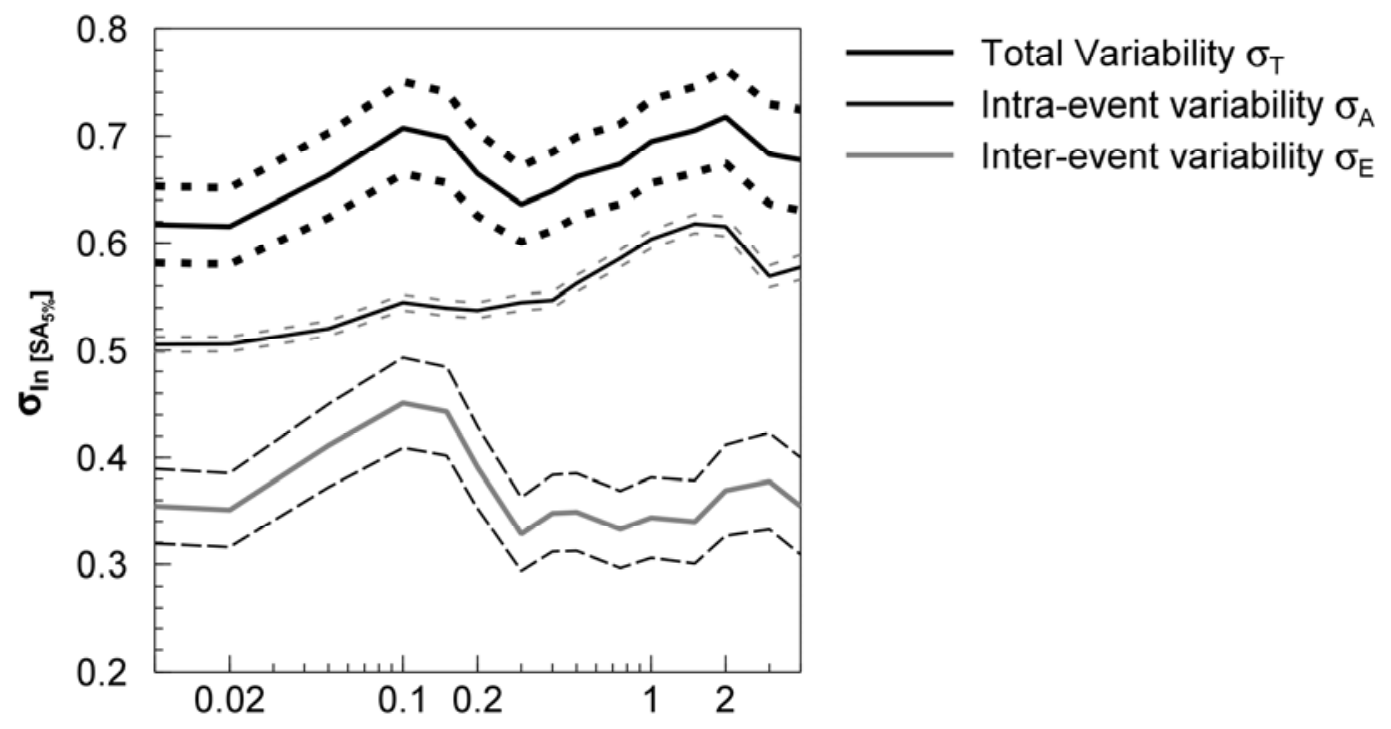

Period T(s) 
Figure 7: Quantile-quantile plot of the total normalised residuals $\left(\varepsilon_{T}\right)$ of Abrahamson and Silva (2005), at selected response periods. The grey-shaded zones at the top and bottom of the plots correspond to sample quantiles outside the range defined by the maximum value of the normalised residual that could be observed for a sample of this size if the residuals were normally distributed $\left(\varepsilon^{*}\right.$ max $)$.

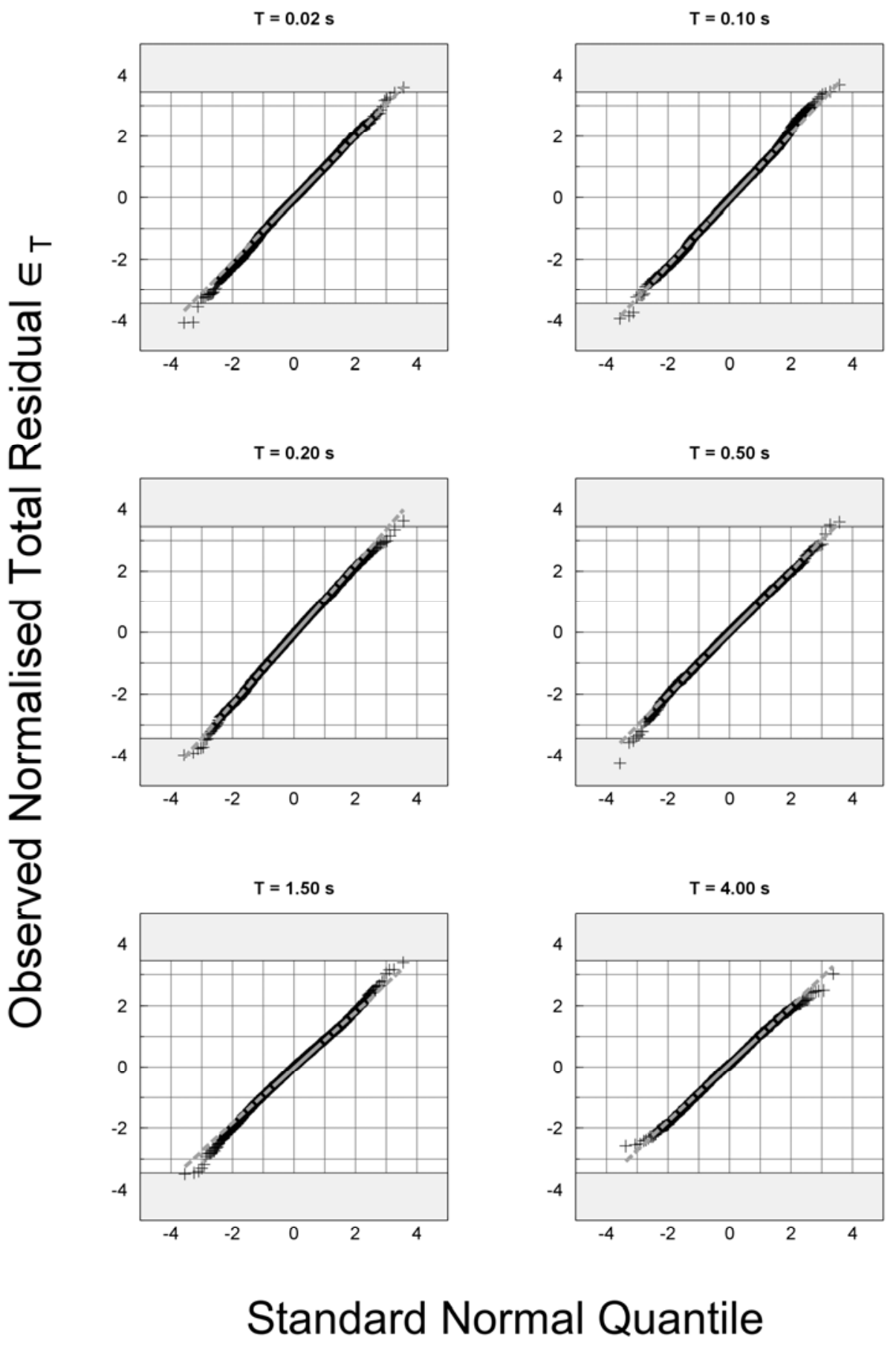


Figure 8: Quantile-quantile plot of the normalised intra-event residuals $\left(\varepsilon_{\mathrm{A}}\right)$ of $\underline{\text { Abrahamson and }}$ Silva (2005), at selected response periods.

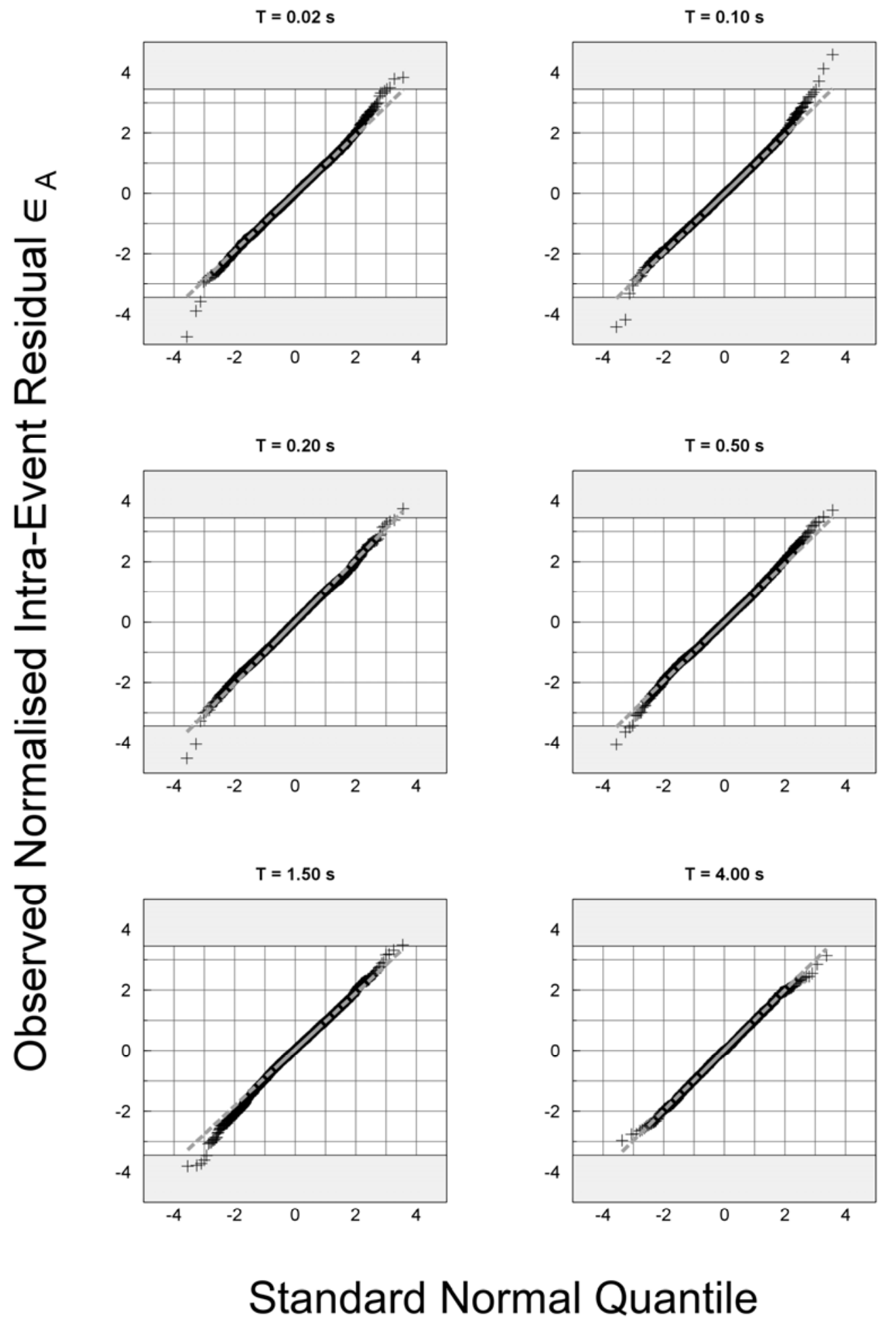


Figure 9: Contribution of selected events to the dataset used in regression (top), and to the high$\varepsilon_{\mathrm{T}}$ selection (bottom), for the Abrahamson and Silva (2005) dataset.
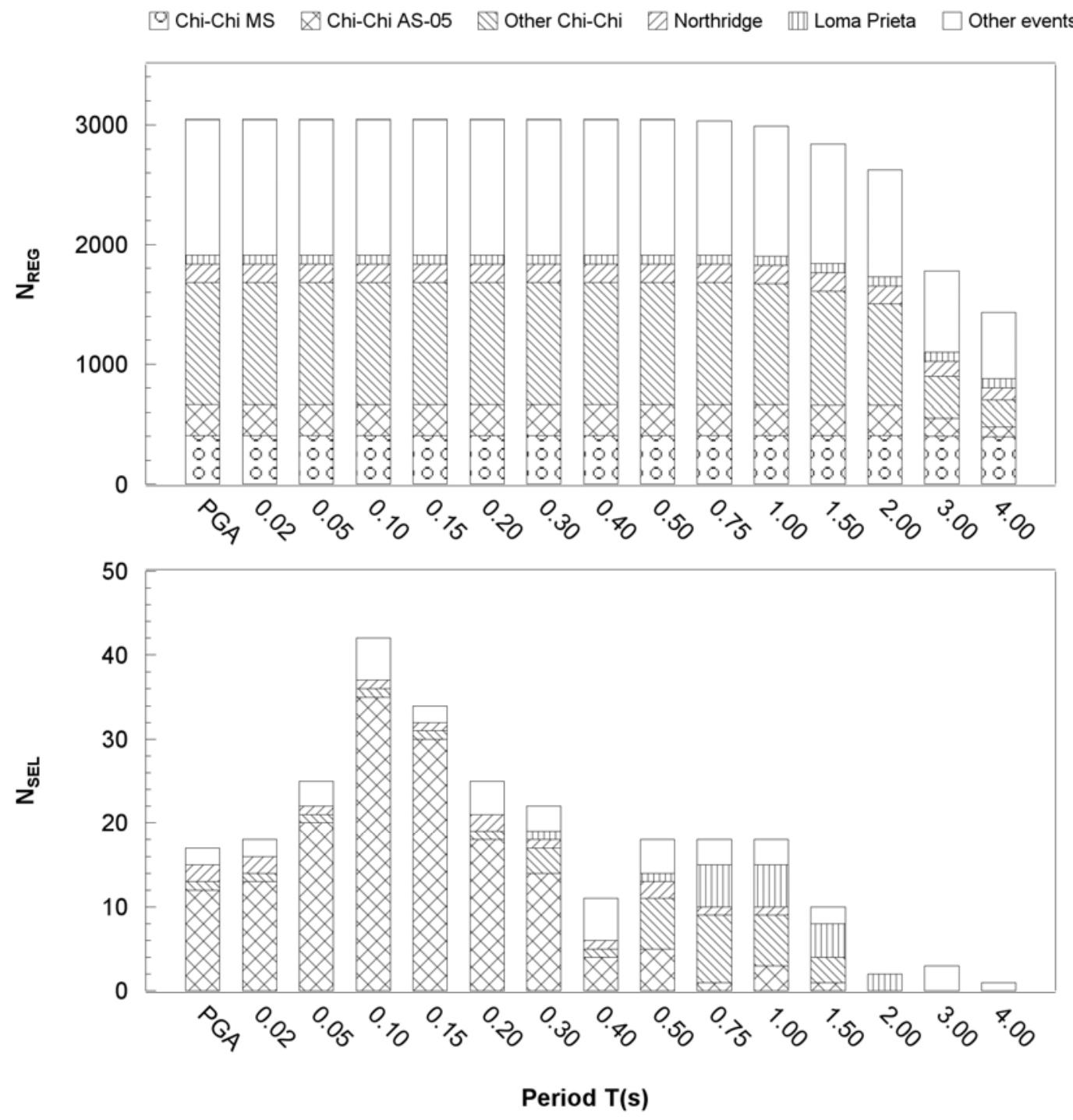
Figure 10: Normalised inter-event residuals for events of the Chi-Chi, Taiwan, sequence. The dashed lines give the envelope from all events in the Abrahamson and Silva (2005) dataset.

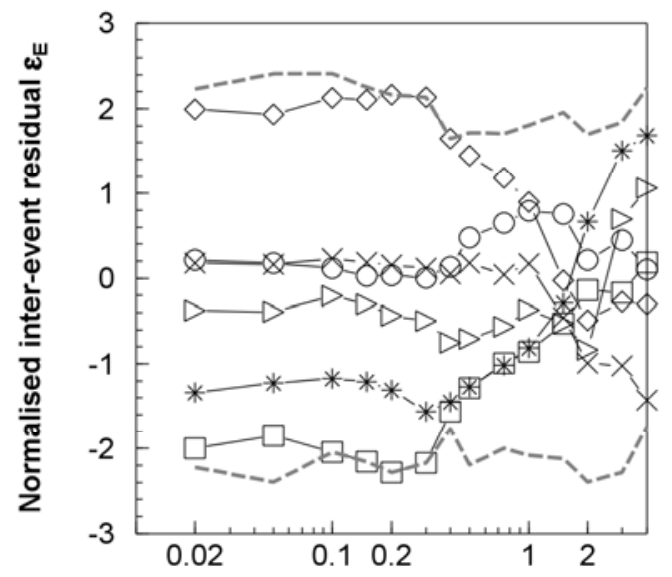

$\square-\square$ Chi-Chi Mainshock (NGA EQ\#137)

$\times \longrightarrow \times$ Aftershock Chi-Chi-02 (NGA EQ \# 171)

* * Aftershock Chi-Chi-03 (NGA EQ \# 172)

$\triangleright \longrightarrow$ Aftershock Chi-Chi-04 (NGA EQ \# 173)

$\diamond \prec$ Aftershock Chi-Chi-05 (NGA EQ \# 174)

$\bigcirc-O$ Aftershock Chi-Chi-06 (NGA EQ \# 175)

----- Envelope (all events)

Period T(s) 
Figure 11: Normalised total and intra-event residuals from the Abrahamson and Silva (2005) model associated with records from the TCU array, for the Chi-Chi mainshock (EQ \#137) and aftershocks Chi-Chi-05 (EQ \#174) and Chi-Chi-06 (EQ\#175).

TCU Array - Chi-Chi Mainshock (NGA EQ \#137)
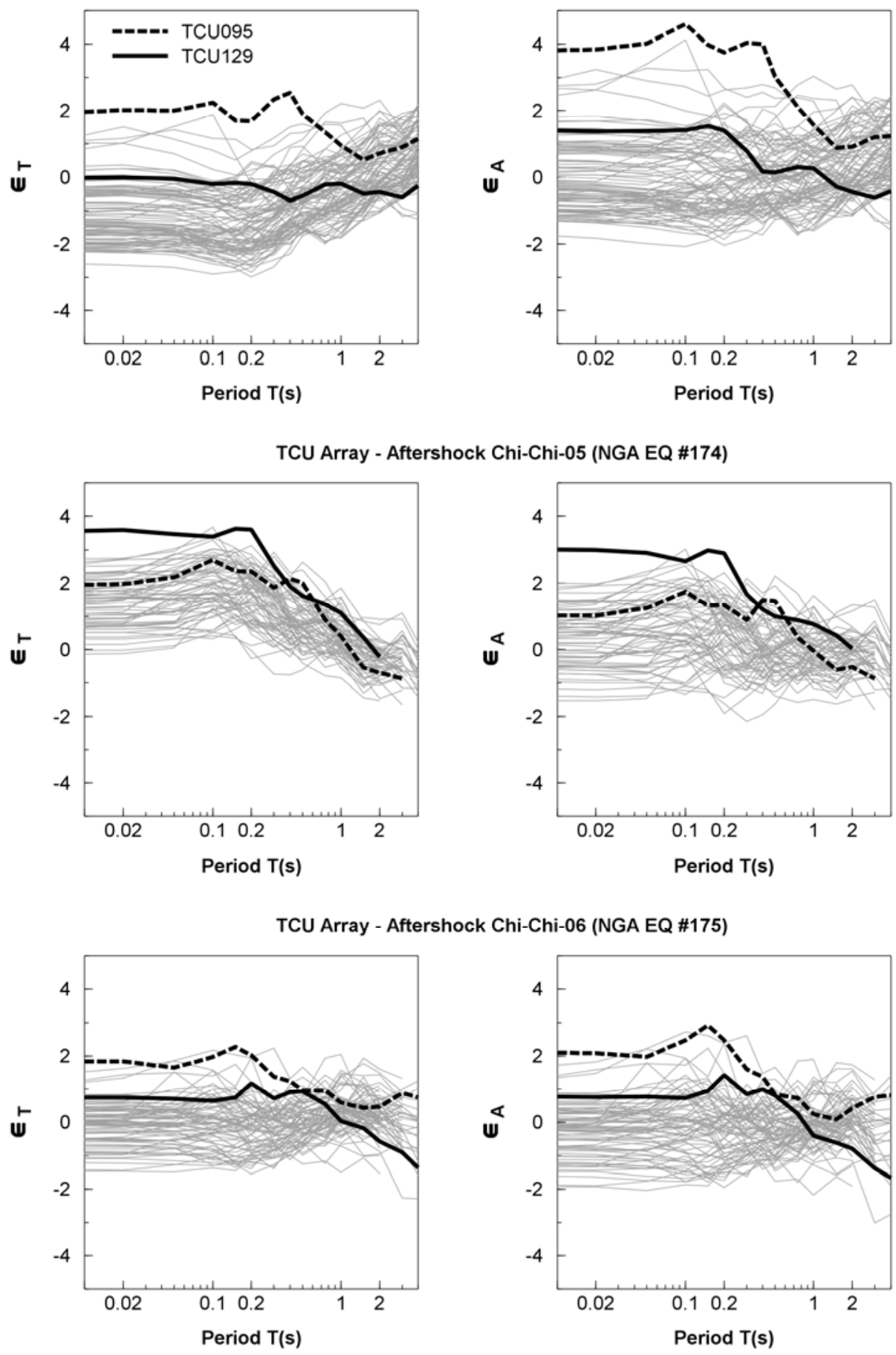


\section{Tables}

Table 1: Truncation levels corresponding to characteristic thresholds on the conditional probability of exceedance (POE) of ground motion.

\begin{tabular}{|c|c|}
\hline Conditional POE & $\boldsymbol{\varepsilon}_{\max }$ based on conditional POE \\
\hline $10^{-1}$ & 1.28 \\
\hline $10^{-2}$ & 2.32 \\
\hline $10^{-3}$ & 3.09 \\
\hline $10^{-4}$ & 3.72 \\
\hline $10^{-5}$ & 4.26 \\
\hline $10^{-6}$ & 4.75 \\
\hline
\end{tabular}


Table 2: Summary of maximum normalised residuals in the datasets associated with a selection of recent ground-motion prediction equations.

\begin{tabular}{|c|c|c|c|c|c|c|c|c|}
\hline Equation & Period & $\begin{array}{c}\text { Maximum } \\
\varepsilon_{T} \\
\text { observed }\end{array}$ & $\begin{array}{c}\text { Maximum } \\
\varepsilon_{E} \\
\text { observed }\end{array}$ & $\begin{array}{c}\text { Maximum } \\
\varepsilon_{A} \\
\text { observed }\end{array}$ & $\begin{array}{c}\text { Number } \\
\text { of } \\
\text { events } \\
\left(N_{E Q}\right)\end{array}$ & $\begin{array}{c}\text { Number } \\
\text { of } \\
\text { points } \\
\text { (N } \text { NTS }_{\text {PTS }}\end{array}$ & $\varepsilon_{\max }^{*}\left(N_{\mathrm{EQ}}\right)$ & $\varepsilon^{*}{ }_{\max }\left(N_{\mathrm{PTS}}\right)$ \\
\hline \multirow{4}{*}{$\begin{array}{l}\text { Lussou et al. } \\
\quad(2001)\end{array}$} & $0.0 \mathrm{~s}$ & 4.49 & - & - & 102 & 3011 & 2.33 & 3.40 \\
\hline & $0.1 \mathrm{~s}$ & 4.91 & - & - & 102 & 3011 & 2.33 & 3.40 \\
\hline & $0.2 \mathrm{~s}$ & 4.10 & - & - & 102 & 3011 & 2.33 & 3.40 \\
\hline & $1.0 \mathrm{~s}$ & 4.70 & - & - & 102 & 3011 & 2.33 & 3.40 \\
\hline $\begin{array}{c}\text { Chang et al. } \\
(2001)\end{array}$ & $0.0 \mathrm{~s}$ & 4.15 & - & - & 45 & 4754 & 2.01 & 3.53 \\
\hline \multirow{4}{*}{$\begin{array}{l}\text { Berge-Thierry } \\
\text { et al. (2003) }\end{array}$} & $0.0 \mathrm{~s}$ & 3.47 & - & - & 138 & 965 & 2.44 & 3.08 \\
\hline & $0.1 \mathrm{~s}$ & 3.45 & - & - & 138 & 965 & 2.44 & 3.08 \\
\hline & $1.0 \mathrm{~s}$ & 3.06 & - & - & 138 & 965 & 2.44 & 3.08 \\
\hline & $4.0 \mathrm{~s}$ & 2.78 & - & - & 138 & 965 & 2.44 & 3.08 \\
\hline \multirow{6}{*}{$\begin{array}{l}\text { Bommer et al. } \\
\qquad(2003)\end{array}$} & $0.0 \mathrm{~s}$ & 2.72 & 1.33 & 2.75 & 157 & 422 & 2.49 & 2.82 \\
\hline & $0.1 \mathrm{~s}$ & 2.57 & 1.23 & 2.65 & 157 & 422 & 2.49 & 2.82 \\
\hline & $0.2 \mathrm{~s}$ & 2.88 & 1.53 & 2.99 & 157 & 422 & 2.49 & 2.82 \\
\hline & $0.5 \mathrm{~s}$ & 2.95 & 1.58 & 2.88 & 157 & 422 & 2.49 & 2.82 \\
\hline & $1.0 \mathrm{~s}$ & 2.66 & 2.19 & 3.11 & 157 & 422 & 2.49 & 2.82 \\
\hline & $2.0 \mathrm{~s}$ & 2.21 & 1.60 & 2.80 & 157 & 422 & 2.49 & 2.82 \\
\hline \multirow{6}{*}{$\begin{array}{l}\text { Ambraseys et } \\
\text { al. (2005) }\end{array}$} & $0.0 \mathrm{~s}$ & 2.96 & 1.56 & 3.24 & 135 & 595 & 2.44 & 2.93 \\
\hline & $0.1 \mathrm{~s}$ & 2.58 & 1.35 & 3.16 & 135 & 595 & 2.44 & 2.93 \\
\hline & $0.2 \mathrm{~s}$ & 3.74 & 1.57 & 4.08 & 135 & 595 & 2.44 & 2.93 \\
\hline & $0.5 \mathrm{~s}$ & 2.98 & 1.15 & 2.93 & 134 & 592 & 2.43 & 2.93 \\
\hline & $1.0 \mathrm{~s}$ & 2.85 & 2.30 & 2.40 & 116 & 490 & 2.38 & 2.87 \\
\hline & $2.0 \mathrm{~s}$ & 2.89 & 2.09 & 2.21 & 72 & 260 & 2.20 & 2.67 \\
\hline \multirow{6}{*}{$\begin{array}{l}\text { Abrahamson } \\
\text { and Silva } \\
(2005)\end{array}$} & $0.0 \mathrm{~s}$ & 3.57 & 2.25 & 3.81 & 102 & 2791 & 2.33 & 3.38 \\
\hline & $0.1 \mathrm{~s}$ & 3.69 & 2.41 & 4.60 & 102 & 2791 & 2.33 & 3.38 \\
\hline & $0.2 \mathrm{~s}$ & 3.62 & 2.16 & 3.75 & 102 & 2791 & 2.33 & 3.38 \\
\hline & $0.5 \mathrm{~s}$ & 3.58 & 1.71 & 3.69 & 102 & 2790 & 2.33 & 3.38 \\
\hline & $1.0 \mathrm{~s}$ & 3.78 & 1.81 & 4.81 & 98 & 2737 & 2.32 & 3.38 \\
\hline & $2.0 \mathrm{~s}$ & 2.96 & 1.70 & 3.00 & 92 & 2376 & 2.29 & 3.34 \\
\hline \multirow{6}{*}{$\begin{array}{l}\text { Abrahamson } \\
\text { and Silva } \\
(2007)\end{array}$} & $0.0 \mathrm{~s}$ & 3.34 & 4.78 & 4.32 & 129 & 2675 & 2.42 & 3.37 \\
\hline & $0.1 \mathrm{~s}$ & 3.86 & 4.86 & 5.47 & 129 & 2675 & 2.42 & 3.37 \\
\hline & $0.2 \mathrm{~s}$ & 3.10 & 4.43 & 4.24 & 129 & 2675 & 2.42 & 3.37 \\
\hline & $0.5 \mathrm{~s}$ & 3.07 & 3.41 & 3.73 & 129 & 2672 & 2.42 & 3.37 \\
\hline & $1.0 \mathrm{~s}$ & 3.11 & 4.79 & 4.59 & 122 & 2598 & 2.40 & 3.36 \\
\hline & $2.0 \mathrm{~s}$ & 2.73 & 3.48 & 3.03 & 108 & 2250 & 2.36 & 3.32 \\
\hline \multirow{6}{*}{$\begin{array}{c}\text { Boore \& } \\
\text { Atkinson } \\
(2006)\end{array}$} & $0.0 \mathrm{~s}$ & 3.43 & 2.91 & 4.34 & 58 & 1574 & 2.11 & 3.22 \\
\hline & $0.1 \mathrm{~s}$ & 2.99 & 2.25 & 4.78 & 58 & 1574 & 2.11 & 3.22 \\
\hline & $0.2 \mathrm{~s}$ & 2.71 & 2.56 & 4.29 & 58 & 1574 & 2.11 & 3.22 \\
\hline & $0.5 \mathrm{~s}$ & 3.52 & 4.82 & 4.37 & 58 & 1574 & 2.11 & 3.22 \\
\hline & $1.0 \mathrm{~s}$ & 3.21 & 4.57 & 3.62 & 51 & 1561 & 2.06 & 3.22 \\
\hline & $2.0 \mathrm{~s}$ & 2.66 & 3.44 & 3.18 & 41 & 1454 & 1.97 & 3.20 \\
\hline \multirow{6}{*}{$\begin{array}{c}\text { Campbell \& } \\
\text { Bozorgnia } \\
(2006)\end{array}$} & $0.01 \mathrm{~s}$ & 3.77 & 2.14 & 4.46 & 64 & 1561 & 2.15 & 3.22 \\
\hline & $0.1 \mathrm{~s}$ & 3.35 & 2.35 & 4.75 & 64 & 1561 & 2.15 & 3.22 \\
\hline & $0.2 \mathrm{~s}$ & 2.76 & 1.17 & 3.89 & 64 & 1561 & 2.15 & 3.22 \\
\hline & $0.5 \mathrm{~s}$ & 3.74 & 1.80 & 4.19 & 64 & 1560 & 2.15 & 3.22 \\
\hline & $1.0 \mathrm{~s}$ & 3.30 & 1.95 & 3.51 & 64 & 1556 & 2.15 & 3.22 \\
\hline & $2.0 \mathrm{~s}$ & 3.15 & 1.73 & 3.22 & 62 & 1428 & 2.14 & 3.19 \\
\hline \multirow{6}{*}{$\begin{array}{c}\text { Chiou \& } \\
\text { Youngs (2006) }\end{array}$} & $0.01 \mathrm{~s}$ & 3.13 & 1.82 & 4.20 & 131 & 3295 & 2.43 & 3.43 \\
\hline & $0.1 \mathrm{~s}$ & 3.36 & 2.09 & 3.84 & 131 & 3295 & 2.43 & 3.43 \\
\hline & $0.2 \mathrm{~s}$ & 3.36 & 1.72 & 3.45 & 131 & 3295 & 2.43 & 3.43 \\
\hline & $0.5 \mathrm{~s}$ & 3.61 & 2.08 & 3.71 & 131 & 3292 & 2.43 & 3.43 \\
\hline & $1.0 \mathrm{~s}$ & 4.35 & 2.56 & 5.38 & 124 & 3279 & 2.41 & 3.43 \\
\hline & $2.0 \mathrm{~s}$ & 3.32 & 2.03 & 3.38 & 108 & 2803 & 2.36 & 3.38 \\
\hline
\end{tabular}


Table 3: Summary of events contributing "high- $\varepsilon_{T}$ records" to the selection. $N_{R E G}$ is the number of records contributed by the event to the Abrahamson and Silva (2005) regression (which may vary with period), whereas $\mathrm{N}_{\mathrm{SEL}}$ is the number of records with $\varepsilon_{T} \geq 2.5$ for at least one of the response periods listed in the text, for each of the ground-motion prediction models considered. The magnitude $\left(\mathrm{M}_{\mathrm{W}}\right)$, style-of-faulting (SoF) and event identification number (EQ\#) are those tabulated in the PEER-NGA database.

\begin{tabular}{|c|c|c|c|c|c|c|c|c|c|c|c|}
\hline \multicolumn{2}{|r|}{ CATEGORY } & $\mathbf{N}_{\text {REG }}$ & $\mathbf{M}_{\mathbf{w}}$ & SoF $^{\dagger}$ & $\begin{array}{c}\mathrm{EQ} \\
\#\end{array}$ & EVENT NAME & $\begin{array}{c}\mathrm{N}_{\mathrm{SEL}} \\
\mathrm{AS}^{1} 5^{1}\end{array}$ & $\begin{array}{c}\mathrm{N}_{\mathrm{SEL}} \\
\mathrm{ASO7}^{2}\end{array}$ & $\begin{array}{c}\mathrm{N}_{\mathrm{SEL}} \\
\text { BA06 }^{3}\end{array}$ & $\begin{array}{c}\mathrm{N}_{\mathrm{SEL}} \\
\mathrm{CB}^{4}{ }^{4}\end{array}$ & $\begin{array}{r}\mathrm{N}_{\mathrm{SEL}} \\
\mathrm{CY}^{5}{ }^{5}\end{array}$ \\
\hline \multirow{6}{*}{ I } & \multirow{6}{*}{ CHI-CHI DATA } & $399-406$ & 7.62 & $\mathrm{RO}$ & 137 & Chi-Chi - 01 & 1 & 7 & 3 & 5 & 5 \\
\hline & & $3-280$ & 5.90 & RV & 171 & Chi-Chi - 02 & 1 & 0 & $0^{*}$ & $0^{*}$ & 2 \\
\hline & & $71-235$ & 6.20 & $\mathrm{RV}$ & 172 & Chi-Chi - 03 & 4 & 2 & $0^{*}$ & $0^{*}$ & 30 \\
\hline & & $66-237$ & 6.20 & SS & 173 & Chi-Chi - 04 & 1 & 1 & $0^{*}$ & $0^{*}$ & 10 \\
\hline & & $79-254$ & 6.20 & $\mathrm{RV}$ & 174 & Chi-Chi - 05 & 56 & 29 & $0^{*}$ & $0^{*}$ & 30 \\
\hline & & $82-268$ & 6.30 & RV & 175 & Chi-Chi - 06 & 10 & 8 & $0^{*}$ & $0^{*}$ & 35 \\
\hline \multirow{5}{*}{ II } & \multirow{5}{*}{$\begin{array}{c}\text { WELL- } \\
\text { RECORDED } \\
\text { EVENTS } \\
\left(N_{\text {REG }} \geq 45\right. \\
\text { for AS05) }\end{array}$} & $43-47$ & 6.36 & RV & 76 & Coalinga-01 & 2 & 3 & 4 & 4 & 7 \\
\hline & & $10-112$ & 5.99 & $\mathrm{RO}$ & 113 & Whittier Narrows-01 & 1 & 1 & 1 & 1 & 1 \\
\hline & & $76-77$ & 6.93 & RO & 118 & Loma Prieta & 9 & 7 & 8 & 11 & 13 \\
\hline & & $102-154$ & 6.69 & $\mathrm{RV}$ & 127 & Northridge-01 & 3 & 2 & 0 & 1 & 3 \\
\hline & & $2-48$ & 5.28 & $\mathrm{RV}$ & 151 & Northridge-06 & 1 & 1 & 0 & 0 & 0 \\
\hline \multirow{6}{*}{ III } & \multirow{6}{*}{$\begin{array}{c}\text { INTERMEDIATELY } \\
\text { WELL } \\
\text { RECORDED } \\
\text { EVENTS } \\
\left(N_{\text {REG }} \geq 10 \text { and }\right. \\
N_{\text {REG }}<45 \\
\text { for AS05) }\end{array}$} & $0-16$ & 5.01 & SS & 51 & Imperial Valley-07 & 1 & 1 & 0 & 0 & 1 \\
\hline & & $7-12$ & 6.90 & NR & 68 & Irpinia-01 & 1 & 0 & 1 & 1 & 2 \\
\hline & & $7-11$ & 5.77 & RV & 80 & Coalinga-05 & 1 & 2 & 0 & 0 & 0 \\
\hline & & $20-26$ & 7.28 & SS & 125 & Landers & 1 & 0 & 0 & 0 & 0 \\
\hline & & $19-21$ & 6.90 & SS & 129 & Kobe & 2 & 1 & 1 & 1 & 2 \\
\hline & & $23-24$ & 5.00 & SS & 160 & Yountville & 1 & 0 & 2 & 4 & 5 \\
\hline \multirow{7}{*}{ IV } & \multirow{7}{*}{$\begin{array}{c}\text { POORLY } \\
\text { RECORDED } \\
\text { EVENTS } \\
\left(N_{\text {REG }}<10\right. \\
\text { for AS05) }\end{array}$} & $5-6$ & 5.80 & SS & 53 & Livermore-01 & 1 & 0 & 0 & 1 & 1 \\
\hline & & $3-6$ & 5.90 & SS & 61 & Westmorland & 1 & 0 & 0 & 0 & 0 \\
\hline & & $0-2$ & 5.21 & $\mathrm{RV}$ & 73 & Coalinga-07 & 1 & 1 & 1 & 1 & 1 \\
\hline & & $2-5$ & 5.94 & SS & 82 & Mammoth Lakes-06 & 3 & 1 & 0 & 0 & 0 \\
\hline & & $1-3$ & 5.10 & NR & 88 & Borah Peak, ID-02 & 1 & 0 & 0 & 0 & 1 \\
\hline & & 5 & 7.37 & SS & 144 & Manjil, Iran & 1 & 0 & 1 & 1 & 1 \\
\hline & & 9 & 5.31 & SS & 165 & $\begin{array}{l}\text { CA/Baja Border } \\
\text { Area }\end{array}$ & 1 & 1 & 0 & 2 & 3 \\
\hline
\end{tabular}

${ }^{1}$ AS05 = Abrahamson \& Silva (2005) $\quad{ }^{2}$ AS07 = Abrahamson \& Silva (2007) $\quad{ }^{3}$ BA06 = Boore \& Atkinson (2006)

${ }^{4}$ CB06=Campbell \& Bozorgnia (2006) ${ }^{5}$ CY06 $=$ Chiou \& Youngs (2006)

${ }^{\dagger} \mathrm{RV}=$ reverse; $\mathrm{RO}=$ reverse-oblique; $\mathrm{SS}=$ strike-slip; $\mathrm{NR}=$ normal

* Event not used in the regression 